\title{
THE EFFECT OF DISTRIBUTED ENERGY RESOURCE COMPETITION WITH CENTRAL GENERATION
}

\section{October 2003}

Prepared by

S. W. Hadley

J. W. Van Dyke

T. K. Stovall 


\title{
DOCUMENT AVAILABILITY
}

Reports produced after January 1, 1996, are generally available free via the U.S. Department of Energy (DOE) Information Bridge:

Web site: http://www.osti.gov/bridge

Reports produced before January 1, 1996, may be purchased by members of the public from the following source:

\author{
National Technical Information Service \\ 5285 Port Royal Road \\ Springfield, VA 22161 \\ Telephone: 703-605-6000 (1-800-553-6847) \\ TDD: 703-487-4639 \\ Fax: 703-605-6900 \\ E-mail: info@ntis.fedworld.gov \\ Web site: http://www.ntis.gov/support/ordernowabout.htm
}

Reports are available to DOE employees, DOE contractors, Energy Technology Data Exchange (ETDE) representatives, and International Nuclear Information System (INIS) representatives from the following source:

Office of Scientific and Technical Information

P.O. Box 62

Oak Ridge, TN 37831

Telephone: $865-576-8401$

Fax: 865-576-5728

E-mail: reports@adonis.osti.gov

Web site: http://www.osti.gov/contact.html

This report was prepared as an account of work sponsored by an agency of the United States Government. Neither the United States government nor any agency thereof, nor any of their employees, makes any warranty, express or implied, or assumes any legal liability or responsibility for the accuracy, completeness, or usefulness of any information, apparatus, product, or process disclosed, or represents that its use would not infringe privately owned rights. Reference herein to any specific commercial product, process, or service by trade name, trademark, manufacturer, or otherwise, does not necessarily constitute or imply its endorsement, recommendation, or favoring by the United States Government or any agency thereof. The views and opinions of authors expressed herein do not necessarily state or reflect those of the United States Government or any agency thereof. 


\title{
THE EFFECT OF DISTRIBUTED ENERGY RESOURCE COMPETITION WITH CENTRAL GENERATION
}

\author{
S. W. Hadley \\ J. W. Van Dyke \\ T. K. Stovall
}

October 2003

\author{
Sponsored by \\ Department of Energy \\ Office of Energy Efficiency and Renewable Energy \\ OAK RIDGE NATIONAL LABORATORY \\ Oak Ridge, Tennessee 37831 \\ managed by \\ UT-BATTELLE, LLC \\ for the \\ U.S. DEPARTMENT OF ENERGY \\ under contract No. DE-AC05-00OR22725
}





\section{CONTENTS}

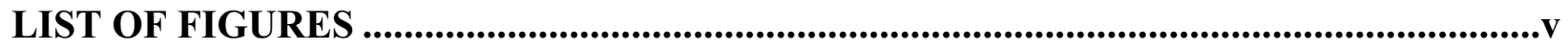

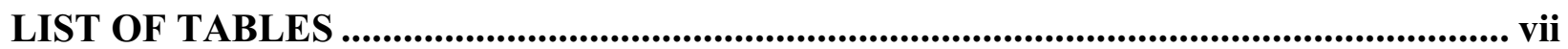

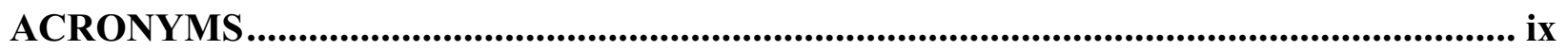

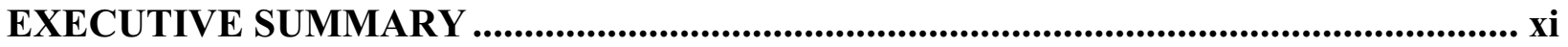

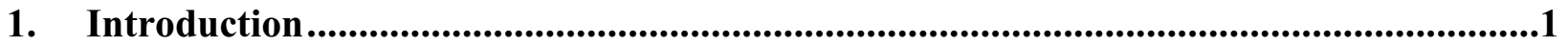

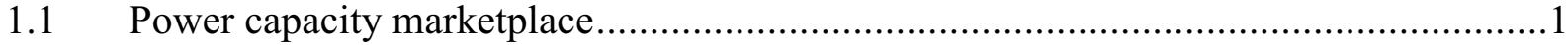

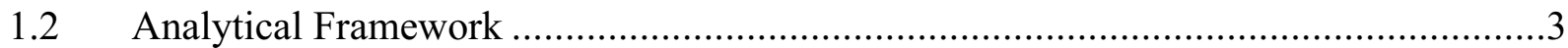

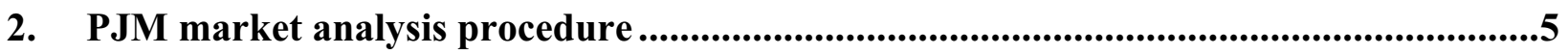

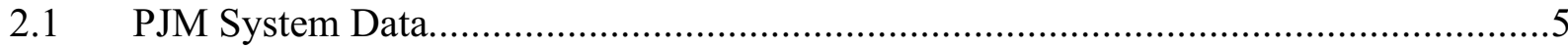

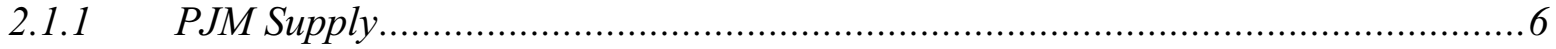

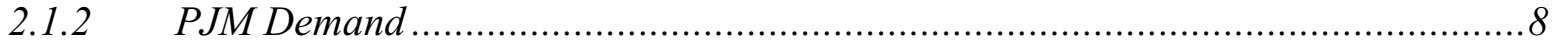

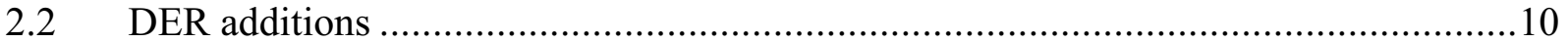

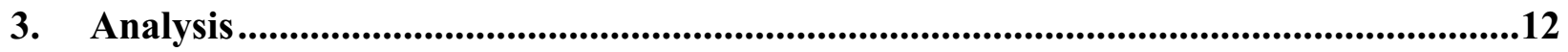

3.1 DER adds to reserve margin ...................................................................... 12

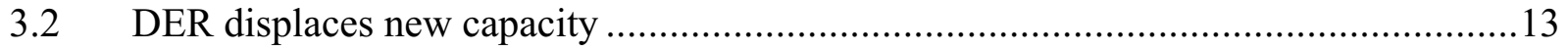

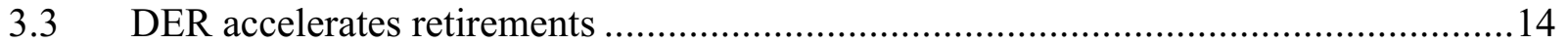

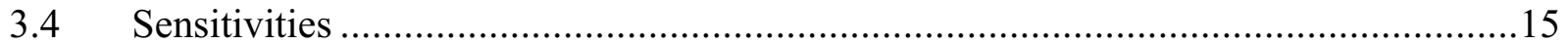

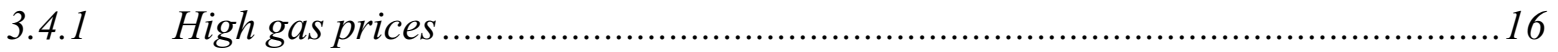

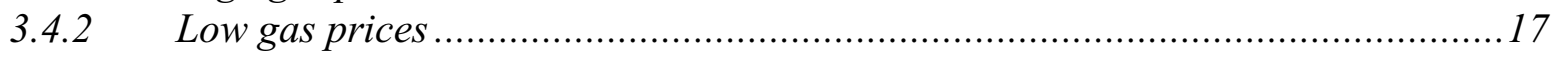

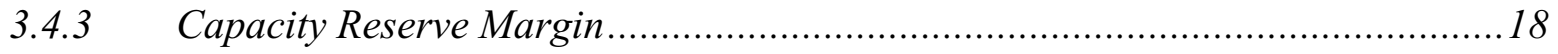

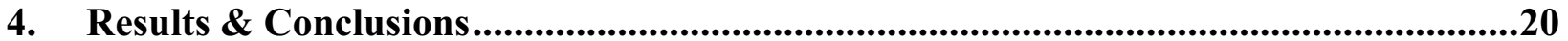

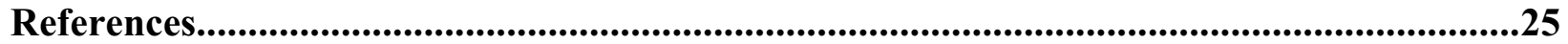





\section{LIST OF FIGURES}

Figure ES-1. Central generation displaced by DER operating year-round in different scenarios xii

Figure ES-2. Central generation displaced by DER operating weekdays only in different scenarios. xii

Figure 1. Load Duration Curve and different power plant classes ...........................................2

Figure 2. PJM region including all or parts of Pennsylvania, New Jersey, Maryland, and Delaware.

Figure 3. Fuel prices from EIA's Annual Energy Outlook (AEO), Short-Term Energy Outlook

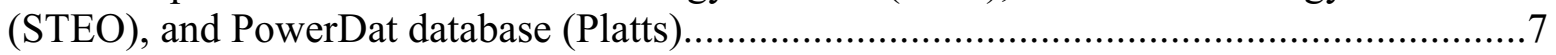

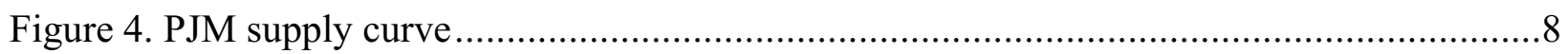

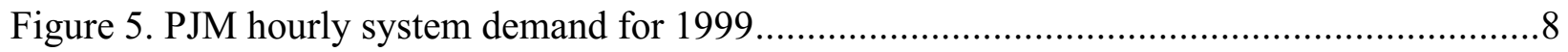

Figure 6. Plants dispatched during the peak season by fuel type .............................................

Figure 7. Plants dispatched during the off-peak season by fuel type..........................................

Figure 8. Annual LDCs with no DER, Peaking DER, and Baseload DER removed from demand

Figure 9. Generation displaced by DER if no central capacity cancelled or retired.....................12

Figure 10. Generation displaced by DER if $2000 \mathrm{MW}$ of CC capacity is cancelled compared to if no capacity is cancelled ............................................................................................. 14

Figure 12. Generation displaced by DER if $2000 \mathrm{MW}$ of existing capacity is retired compared to if no capacity retired

Figure 13. Generation displaced with new CC capacity cancelled and reference (Platts) and high (STEO) gas prices 16

Figure 14. Generation displaced with capacity cancelled and reference (Platts) and low (AEO) gas prices.

Figure 15. Displaced generation with $2000 \mathrm{MW}$ of Peaking DER, low gas prices, and varying amounts of CC capacity cancelled

Figure 16. Generation displaced with new CC capacity cancelled and reference and low customer demands

Figure 17. Central generation displaced by DER operating year-round in different scenarios ....20

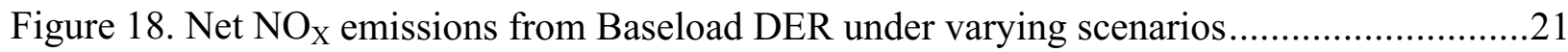

Figure 19. Central generation displaced by DER operating weekdays only in different scenarios

Figure 20. Net $\mathrm{NO}_{\mathrm{X}}$ emissions from Peaking DER under varying scenarios 



\section{LIST OF TABLES}

Table ES-1. Net changes in energy and emissions as a fraction of the DER's amounts for all scenarios studied.

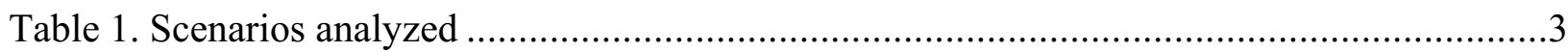

Table 2. New capacity planned for MAAC region (Platts 2003) ............................................6

Table 3. Average fuel prices used in study, \$/mmBtu .......................................................

Table 4. Distributed generation (with CHP) and alternative technologies .............................11

Table 5. Generation displaced by DER if no central capacity cancelled or retired (GWh) .........12

Table 6. Energy and emissions parameters of displaced generation .......................................12

Table 7. Primary energy use, $\mathrm{CO}_{2}, \mathrm{NO}_{\mathrm{x}}$, and $\mathrm{SO}_{2}$ emissions from $2000 \mathrm{MW}$ of Combustion Turbine-6B with and without CHP if no generation is cancelled or retired ......................13

Table 8. Generation displaced by DER if $2000 \mathrm{MW}$ of CC capacity is cancelled (GWh) ..........14

Table 9. Primary energy use, $\mathrm{CO}_{2}, \mathrm{NO}_{\mathrm{x}}$, and $\mathrm{SO}_{2}$ emissions from $2000 \mathrm{MW}$ of Combustion Turbine-6B with and without CHP if $2000 \mathrm{MW}$ of CC capacity is cancelled ....................14

Table 10. Generation displaced by DER if $2000 \mathrm{MW}$ of existing capacity is retired (GWh)......15

Table 11. Primary energy use, $\mathrm{CO}_{2}, \mathrm{NO}_{\mathrm{x}}$, and $\mathrm{SO}_{2}$ emissions from $2000 \mathrm{MW}$ of Combustion Turbine-6B with and without CHP if $2000 \mathrm{MW}$ of existing capacity is retired................15

Table 12. Generation displaced with capacity cancelled and high (STEO) gas prices (GWh)....16

Table 13. Primary energy use, $\mathrm{CO}_{2}, \mathrm{NO}_{\mathrm{x}}$, and $\mathrm{SO}_{2}$ emissions from $2000 \mathrm{MW}$ of CT-6B with and without CHP if $2000 \mathrm{MW}$ of new CC capacity is cancelled and gas prices are higher ........16

Table 14. Generation displaced with capacity cancelled and low gas prices (GWh) ................17

Table 15. Energy and emissions parameters of displaced generation................................... 17

Table 16. Primary energy use, $\mathrm{CO}_{2}, \mathrm{NO}_{\mathrm{x}}$, and $\mathrm{SO}_{2}$ emissions from $2000 \mathrm{MW}$ of CT-6B with and without CHP if $2000 \mathrm{MW}$ of new CC capacity is cancelled and gas prices are lower ........18

Table 17. Generation displaced with capacity cancelled and low customer demands (GWh).....19

Table 18. Primary energy use, $\mathrm{CO}_{2}, \mathrm{NO}_{\mathrm{x}}$, and $\mathrm{SO}_{2}$ emissions from $2000 \mathrm{MW}$ of CT-6B with and without CHP if $2000 \mathrm{MW}$ of new CC capacity is cancelled and customer demands are lower

Table 19. Net changes in energy and emissions as a fraction of the DER's amounts for all scenarios studied.... 



\section{ACRONYMS}

AEO

$\mathrm{CC}$

CHP

CT

DER

EIA

EPA

GWh

LDC

MWh

mmBtu

O\&M

PJM

ST

STEO

TWh
Annual Energy Outlook

Combined Cycle

Combined Heat and Power

Combustion Turbine

Distributed Energy Resource

Energy Information Administration

Environmental Protection Agency

GigaWatt-hour $=1,000 \mathrm{MWh}$

Load Duration Curve

MegaWatt-hour

million British thermal units

Operations and Maintenance

Pennsylvania, New Jersey, Maryland Interconnection LLC

Steam Turbine

Short Term Energy Outlook

TeraWatt-hour $=1,000 \mathrm{GWh}$ 


\section{EXECUTIVE SUMMARY}

Distributed Energy Resource (DER) has been touted as a clean and efficient way to generate electricity at end-use sites, potentially allowing the exhaust heat to be put to good use as well. However, despite its environmental acceptability compared to many other types of generation, it has faced some disapproval because it may displace other, cleaner generation technologies. The end result could be more pollution than if the DER were not deployed. However, the DER may actually be competing against older power plants instead. If the DER is built then these other plants may be retired sooner, reducing their emissions. Or it may be that DER does not directly compete against either new or old plant capacity at the decisionmaker level, and increased DER simply reduces the amount of time various plants operate.

The key factor is what gets displaced if DER is added. For every kWh made by DER a kWh (or more with losses) of other production is not made. If enough DER is created, some power plants will not get built so not only their production but also their capacity is displaced.

In a previous paper (Hadley et al, 2003) we examined the changes to system operations if we introduce a small amount of DER. We chose to model the Mid-Atlantic Area Council, one of the reliability councils in the North American Electric Reliability Council. We used the Oak Ridge Competitive Electricity Dispatch (ORCED) model to simulate the addition of 100 MW of DER into the region based on 1999 demands. We could then see how other plants changed operations, with a consequent change in energy use and air emissions.

For this study, we examined the changes in an electric system if a relatively large amount of DER (2000 MW) were introduced. Two main DER scenarios were evaluated: DER operating all the time and DER operating only during weekdays. We created three options: 1) there was no other change in the system's capacity, 2) an equivalent amount of new gas-fired combined cycle (CC) capacity was not built, and 3) the oldest and least-economic of existing capacity was retired. We also conducted several sensitivities on changes in fuel prices and over-all level of system reserves.

Note that we did not analyze whether 2000 MW would be built, could be built, or should be built, but rather what is the impact if it is built. From these options, we can see what impact DER has on the system. Does DER displace CC production on a one-for-one basis or are other technologies also affected? What are the net overall emission changes? What influence does fuel price or excess capacity have on the amount and type of capacity displaced? How much does utilization of the exhaust heat in combined heat and power (CHP) applications influence the overall impact? And, given the market as defined in the model, will new or old capacity more likely be affected by the growth of DER?

The results were evaluated in two key ways: which central power plants declined in production due to the addition of the DER, and what was the consequent change in energy use and emissions. While the conventional wisdom is that additions of DER will automatically displace new combined cycle production, we found that that was not totally correct. In the cases with baseload DER, multiple types of production were displaced, even if gas CC capacity was cancelled in response to the DER (Figure ES-1). Only the case with the low gas prices $(\$ 3.25 / \mathrm{mmBtu})$ and cancellation of new capacity shows an overwhelming amount of displacement of CC production with DER. In the others, significant amounts of coal and oil capacity were also displaced. 
Figure ES-1. Central generation displaced by DER operating year-round in different scenarios

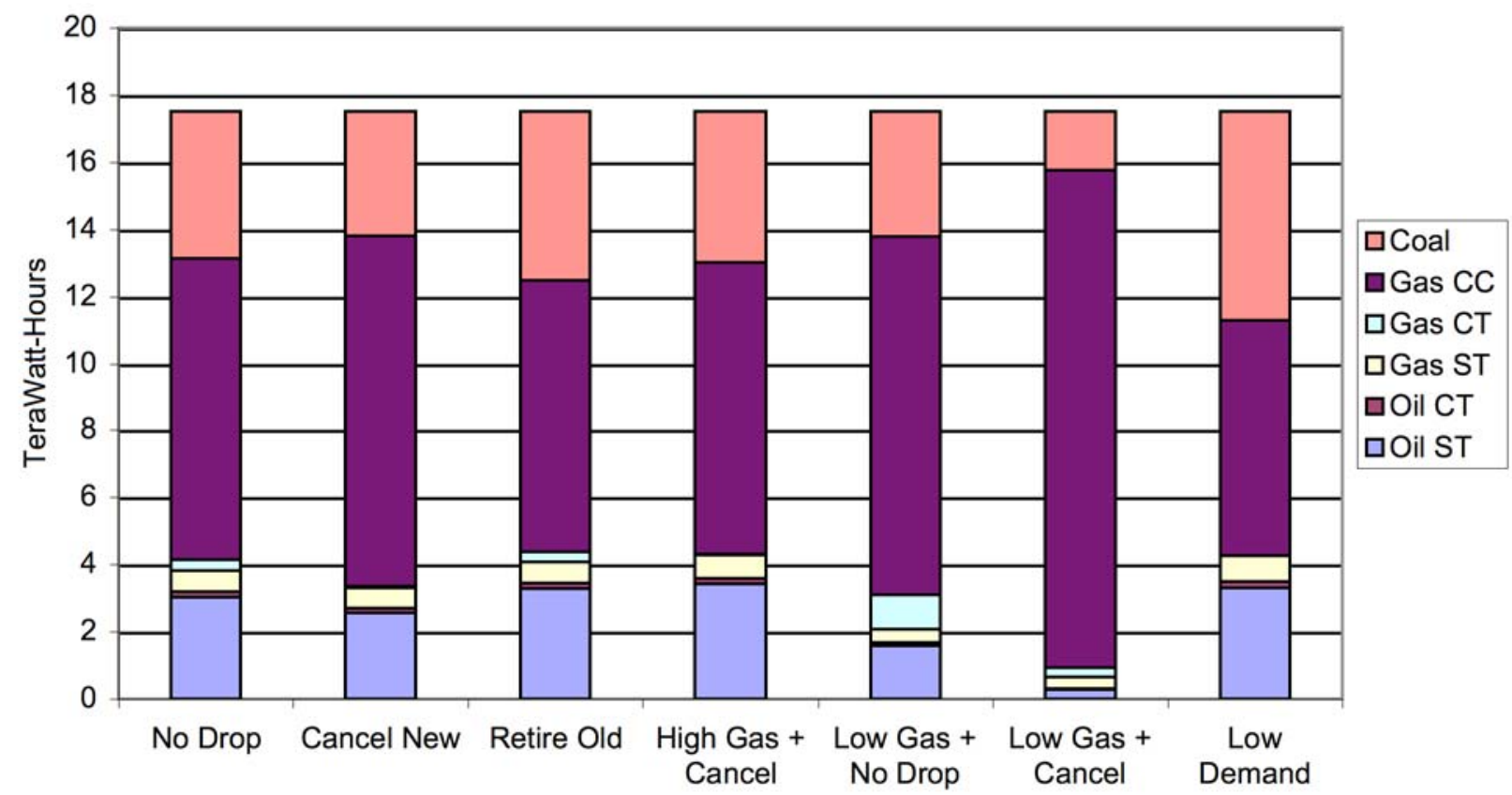

In the scenarios with DER operating only during weekdays there was a similar pattern, but a higher proportion of displaced generation came from gas CC (Figure ES-2). In the one case with low gas prices and cancelled CC plants, the amount of CC production declined so much (due to cancellation) that other central plants increased their production to make up the deficit. Otherwise, the displacement caused by DER production came from multiple technologies.

Figure ES-2. Central generation displaced by DER operating weekdays only in different scenarios

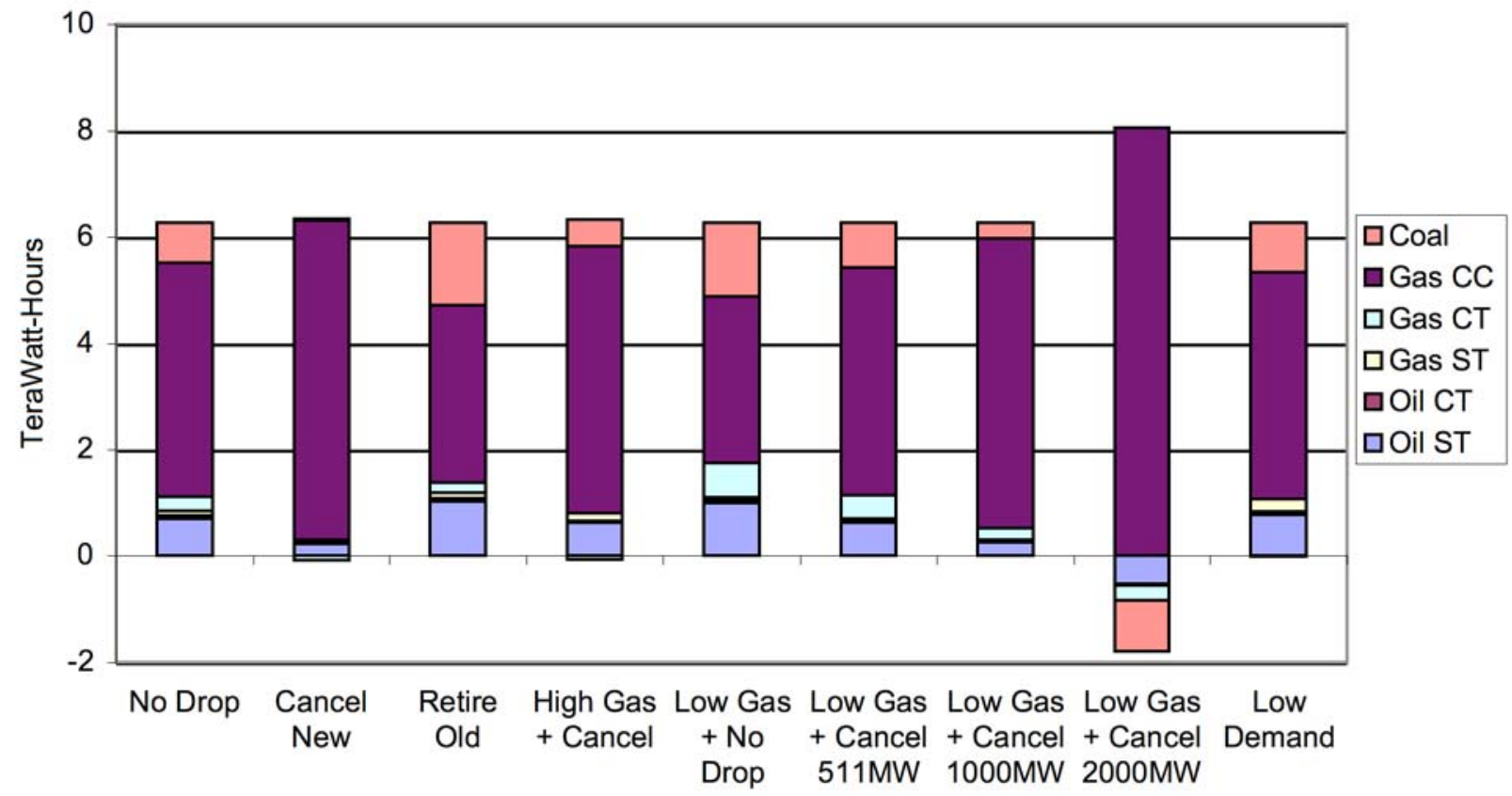


Table ES-1 shows the net primary energy (fuel) and emissions changes from all of the scenarios studied, as a fraction of the fuel used or emissions from the DER. Without CHP, the fuel use and consequent $\mathrm{CO}_{2}$ emissions from the DER was greater than the displaced central generation so that the net change was positive. But with $\mathrm{CHP}$, the net fuel use and $\mathrm{CO}_{2}$ releases were less than the combined displaced electric generation plus displaced thermal energy production, so the net ratio is negative. $\mathrm{NO}_{\mathrm{X}}$ emissions from DER were very low so that net emissions were negative even with just electricity generation.

Table ES-1. Net changes in energy and emissions as a fraction of the DER's amounts for all scenarios studied. Positive means a net increase and negative means a net savings. NO$_{\mathrm{x}}$ changes are shown as a ratio to the DER emissions. $\mathrm{SO}_{2}$ changes are "+" or "_" since DER emits no $\mathrm{SO}_{2}$.

\begin{tabular}{|c|c|c|c|c|c|c|c|c|c|c|c|}
\hline \multirow[t]{2}{*}{$\begin{array}{l}\text { System } \\
\text { change }\end{array}$} & \multirow[t]{2}{*}{\begin{tabular}{|c|} 
Fuel \\
prices
\end{tabular}} & \multirow[t]{2}{*}{ Demand } & \multirow[t]{2}{*}{$\begin{array}{l}\text { DER } \\
\text { mode }\end{array}$} & \multicolumn{2}{|c|}{$\begin{array}{l}\text { Primary Energy } \\
\text { (fuel) Used }\end{array}$} & \multicolumn{2}{|c|}{$\mathrm{CO}_{2}$} & \multicolumn{2}{|c|}{$\mathrm{NO}_{\mathrm{x}}$} & \multicolumn{2}{|c|}{$\mathrm{SO}_{2}$} \\
\hline & & & & $\begin{array}{l}\mathrm{No} \\
\mathrm{CHP}\end{array}$ & $\begin{array}{l}\text { With } \\
\text { CHP }\end{array}$ & $\begin{array}{l}\mathrm{No} \\
\mathrm{CHP}\end{array}$ & $\begin{array}{l}\text { With } \\
\mathrm{CHP}\end{array}$ & $\begin{array}{l}\mathrm{No} \\
\mathrm{CHP}\end{array}$ & $\begin{array}{l}\text { With } \\
\text { CHP }\end{array}$ & $\begin{array}{l}\mathrm{No} \\
\mathrm{CHP}\end{array}$ & $\begin{array}{l}\text { With } \\
\text { CHP }\end{array}$ \\
\hline \multirow{2}{*}{ No cancel } & \multirow{2}{*}{$\begin{array}{l}\text { Platts } \\
\text { (Ref) }\end{array}$} & \multirow{2}{*}{$\begin{array}{r}2006 \\
+10 \%\end{array}$} & Peak & $28 \%$ & $-32 \%$ & $14 \%$ & $-48 \%$ & $-4 x$ & $-17 x$ & - & - \\
\hline & & & Base & $24 \%$ & $-38 \%$ & $24 \%$ & $-38 \%$ & $-6 x$ & $-19 x$ & - & - \\
\hline \multirow{2}{*}{$\begin{array}{c}\text { Cancel } \\
2000 \text { new }\end{array}$} & \multirow{2}{*}{$\begin{array}{l}\text { Platts } \\
\text { (Ref) }\end{array}$} & \multirow{2}{*}{$\begin{array}{r}2006 \\
+10 \%\end{array}$} & Peak & $41 \%$ & $-22 \%$ & $36 \%$ & $-23 \%$ & $+.1 x$ & $-13 x$ & - & - \\
\hline & & & Base & $27 \%$ & $-34 \%$ & $27 \%$ & $-34 \%$ & $-5 x$ & $-18 x$ & - & - \\
\hline \multirow{2}{*}{$\begin{array}{l}\text { Retire } \\
2000 \text { old }\end{array}$} & \multirow{2}{*}{$\begin{array}{l}\text { Platts } \\
\text { (Ref) }\end{array}$} & \multirow{2}{*}{$\begin{array}{r}2006 \\
+10 \%\end{array}$} & Peak & $24 \%$ & $-38 \%$ & $-2 \%$ & $-61 \%$ & $-6 x$ & $-20 x$ & - & - \\
\hline & & & Base & $22 \%$ & $-39 \%$ & $22 \%$ & $-39 \%$ & $-7 x$ & $-20 x$ & - & - \\
\hline \multirow{2}{*}{$\begin{array}{c}\text { Cancel } \\
2000 \text { new }\end{array}$} & \multirow{2}{*}{$\begin{array}{l}\text { STEO } \\
\text { (High) }\end{array}$} & \multirow{2}{*}{$\begin{array}{r}2006 \\
+10 \%\end{array}$} & Peak & $35 \%$ & $-27 \%$ & $23 \%$ & $-36 \%$ & $-2 x$ & $-15 x$ & - & - \\
\hline & & & Base & $24 \%$ & $-38 \%$ & $24 \%$ & $-38 \%$ & $-7 x$ & $-19 x$ & - & - \\
\hline \multirow{2}{*}{$\begin{array}{c}\text { Cancel } \\
2000 \text { new }\end{array}$} & \multirow{2}{*}{$\begin{array}{l}\text { AEO } \\
\text { (Low) }\end{array}$} & \multirow{2}{*}{$\begin{array}{r}2006 \\
+10 \%\end{array}$} & Peak & $51 \%$ & $-11 \%$ & $64 \%$ & $2 \%$ & $+4 x$ & $-9 x$ & + & + \\
\hline & & & Base & $36 \%$ & $-25 \%$ & $36 \%$ & $-25 \%$ & $-2 x$ & $-15 x$ & - & - \\
\hline $\begin{array}{c}\text { Cancel } \\
1000 \text { new }\end{array}$ & \begin{tabular}{|l|} 
AEO \\
(Low) \\
\end{tabular} & $\begin{array}{r}2006 \\
+10 \% \\
\end{array}$ & Peak & $36 \%$ & $-26 \%$ & $31 \%$ & $-31 \%$ & $-1 x$ & $-14 x$ & - & - \\
\hline $\begin{array}{c}\text { Cancel } \\
511 \text { new }\end{array}$ & $\begin{array}{l}\text { AEO } \\
\text { (Low) } \\
\end{array}$ & $\begin{array}{r}2006 \\
+10 \% \\
\end{array}$ & Peak & $29 \%$ & $-32 \%$ & $15 \%$ & $-46 \%$ & $-3 x$ & $-16 x$ & - & - \\
\hline \multirow{2}{*}{ No cancel } & \multirow{2}{*}{$\begin{array}{l}\text { AEO } \\
\text { (Low) }\end{array}$} & \multirow{2}{*}{$\begin{array}{r}2006 \\
+10 \%\end{array}$} & Peak & $23 \%$ & $-39 \%$ & $1 \%$ & $-61 \%$ & $-6 x$ & $-18 x$ & - & - \\
\hline & & & Base & $28 \%$ & $-34 \%$ & $28 \%$ & $-34 \%$ & $-5 x$ & $-18 x$ & - & - \\
\hline \multirow{2}{*}{$\begin{array}{c}\text { Cancel } \\
2000 \text { new }\end{array}$} & \multirow{2}{*}{$\begin{array}{l}\text { Platts } \\
\text { (Ref) }\end{array}$} & \multirow{2}{*}{2006} & Peak & $30 \%$ & $-32 \%$ & $14 \%$ & $-48 \%$ & $-4 x$ & $-17 x$ & - & - \\
\hline & & & Base & $22 \%$ & $-39 \%$ & $22 \%$ & $-39 \%$ & $-8 x$ & $-21 x$ & - & - \\
\hline \multicolumn{4}{|c|}{ Average of all Scenarios } & $30 \%$ & $-32 \%$ & $24 \%$ & $-37 \%$ & $-4 x$ & $-17 x$ & & \\
\hline
\end{tabular}

Four cases are highlighted. Of the reference cases, the case with peaking DER and cancellation of new $\mathrm{CC}$ capacity had the least savings. Without $\mathrm{CHP}$, even $\mathrm{NO}_{\mathrm{X}}$ emissions were higher with DER, but with CHP there were savings in all categories. On the other hand, if old plants are retired, then net savings 
were high. The most damaging scenario to DER was with the peaking scenario, low gas prices, and cancellation of $2000 \mathrm{MW}$ of new CC. The results show a net increase in all categories without CHP and an increase in $\mathrm{CO}_{2}$ and $\mathrm{SO}_{2}$ emissions even with CHP. This is likely the scenario that many have assumed when considering the benefits of DER, but only appears with outdated assumptions on gas prices.

Although the scenarios are not equally likely, the average results of all the scenarios show a striking conclusion. Savings were significant across the broad range of scenarios. Even if new, gas-fired CC capacity was cancelled in proportion to the impact of DER on system loads, energy was saved and net emissions reduced. Utilizing the exhaust heat from the DER compounded the savings and made DER a valuable component of the country's energy portfolio. 


\section{The Effect of Distributed Energy Resource Competition with Central Generation}

\section{Introduction}

Distributed Energy Resource (DER) has been touted as a clean and efficient way to generate electricity at end-use sites, potentially allowing the exhaust heat to be put to good use as well. However, despite its environmental acceptability compared to many other types of generation, it has faced some disapproval because it may displace other, cleaner generation technologies. The end result could be more pollution than if the DER were not deployed. On the other hand, the DER may be competing against older power plants. If the DER is built then these other plants may be retired sooner, reducing their emissions. Or it may be that DER does not directly compete against either new or old plant capacity at the decision-maker level, and increased DER simply reduces the amount of time various plants operate.

The key factor is what gets displaced if DER is added. For every kWh made by DER a kWh (or more with losses) of other production is not made. If enough DER is created, some power plants will get retired or not get built so not only their production but their capacity is displaced.

Various characteristics of the power system in a region will influence how DER impacts the operation of the grid. The growth in demand in the region may influence whether new plants are postponed or old plants retired. The generation mix, including the fuel types, efficiencies, and emission characteristics of the plants in the region will factor into the overall competition. And public policies such as ease of new construction, emissions regulations, and fuel availability will also come into consideration.

\subsection{Power capacity marketplace}

On a day-to-day basis, power plants in a regulated system are called upon to operate based on their incremental operating costs, with some exceptions due to specific requirements of the network. In a wholesale market, bid prices would substitute for incremental operating costs, and some plants with fixed contracts may operate regardless of the wholesale price. Any electricity production from DER will simply mean that demand on the grid is reduced and whichever plant is "on the margin" or the last one called upon to produce will lower their production level.

Besides this day-to-day energy market, there is a longer-term capacity market that gets affected by the DER production. As sales are reduced over a longer period then the growth rate of system power demand is lowered. If new plants are still constructed and old plants continue to be available, then the overall reserve margin will increase. Many of the plants will be called upon for a lower percentage of the year, wholesale prices may be lowered, and a number of the plants will face increased profitability problems.

Power plant owners may respond to the loss of sales in several ways. They may choose to mothball or retire existing plants, postpone or cancel the construction of new plants, or simply face lowered profits (perhaps eventually going bankrupt.) A regulated firm that has multiple plants as well as the distribution system will likely balance its cancellations and retirements depending on the overall economics while independent power producers (IPPs) with a limited portfolio of plants will be more constrained in their decisions. The lack of available capital may dictate cancellations of new plants regardless of their individual economics, just as the boom in plant construction in recent years happened with little consideration of the overall market. 
Since demand fluctuates over the year, some plants will be called on more often than others and any power system will have a mix of supply types. Figure 1 shows an example of the load duration curve (LDC) for a region and the types of plants that are used to fulfill those demands. Some plants are most effective at providing power essentially all the time, or "baseload" power. They typically have low variable costs but may have high fixed costs. Their low variable costs translate into low bid prices or marginal costs, while the fixed costs are best paid for spread over a large amount of sales. Intermediate plants are called on to come on a significant fraction of the year but will still cycle on and off. Peaking plants are called on the least frequently, during high demand times or to meet capacity emergencies. They have the highest marginal costs but typically have low fixed costs, either because of their technology or because they are old, fully depreciated plants.

\section{Figure 1. Load Duration Curve and different power plant classes}

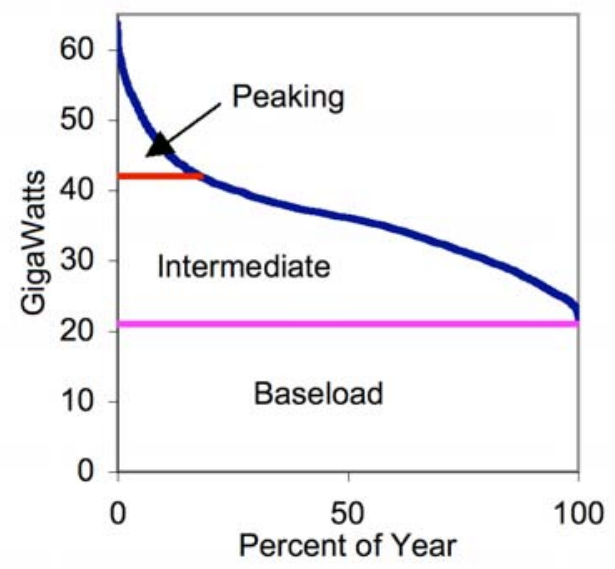

DER operations may be used in any of these modes, depending on the needs of the end-user and the economics involved. Facilities that have a steady requirement for power (and thermal energy if CHP), such as factories or hospitals, may use DER as baseload power. Facilities that have more fluctuating power needs, such as office buildings, may only use DER during operating hours leading more towards peaking or intermediate use. Finally, some facilities may only use DER as emergency capacity in case of actual shortfalls from the grid or very high prices. They may run their DER infrequently, relying on it as a type of insurance rather than as a significant energy producer. (Oftentimes, emissions regulations only allow a DER to run $<200$ hours before more extensive regulations come into play.)

If central system capacity (as opposed to just production) is displaced by DER and the capacity would have had significantly different production amounts than the DER, then other system resources besides the cancelled capacity will be affected. If the cancelled capacity was for peaking purposes and the DER ran as baseload, then other plants will have their production lowered as well since the DER generated more power than the cancelled capacity. On the other hand, if the capacity that gets cancelled was baseload and the DER only operated during peak times, then other capacity will have to run at a higher load level to make up the difference. This residual impact on other technologies can have significant ramifications on the net emissions from the DER, as seen below.

Beyond the potential for delaying new capacity, DER may have a more subtle impact on overall energy use. If new capacity is deferred then advances in the technology, through learning-curve advances or simply diverted interest in research, may also be delayed. However, advances in DER technology would be accelerated. These are likely subtle and immeasurable changes, and would require large penetrations of DER to have an impact.

The relative costs to compare DER to the displaced generation are more difficult to compare. While it may be a simple matter to compare the capital and operating costs of central generation to DER, other factors will take precedence for decision-makers. First, as mentioned above, there may be different decision-makers on whether to build DER or central generation, and these decision-makers will have different capital and fuel cost structures. Integrated utilities use a combination of equity and bondfinancing backed by the strength of the utility; independent power producers are more likely to use project financing based on the future sales from the power plant; DER owners may fund the project through capital improvements budgets of their over-riding business, competing against other non-energy capital projects. 
Fuel costs may be quite different, with large plants purchasing natural gas at wholesale or spot rates while DER owners purchase natural gas at the citygate or commercial rates. On the other hand, central plants may only sell their electricity at wholesale rates while DER owners avoid the purchase of power at higher commercial rates. DER owners using CHP will also be avoiding purchase of fuel for their thermal needs, as well as the capital cost of a separate boiler. All of these factors make it impossible to make blanket statements on the relative cost of DER versus central plants.

\subsection{Analytical Framework}

In a previous paper (Hadley et al 2003) we examined the changes to system operations if we introduce a small amount of DER. We modelled the Mid-Atlantic Area Council, one of the reliability councils in the North American Electric Reliability Council. It is also known as PJM-East, as the Pennsylvania, New Jersey, Maryland Interconnection LLC (PJM) organization has expanded westward in recent years into other reliability council territories. We used the Oak Ridge Competitive Electricity Dispatch (ORCED) model to simulate the addition of $100 \mathrm{MW}$ of DER into the region based on 1999 demands. We could then see how other plants changed operations, with a consequent change in energy use and air emissions.

For this study, we have examined the changes in an electric system if a relatively large amount of DER (2000 MW) were introduced. Note that we did not analyze whether $2000 \mathrm{MW}$ would be built, could be built, or should be built, but rather what is the impact if it is built. We considered three options for the central system: 1) there were no other change in the system's capacity, 2) an equivalent amount of new gas-fired combined cycle (CC) capacity was not built, and 3) the oldest and least-economic of existing capacity was retired. We also conducted several sensitivities on changes in fuel prices and over-all level of system reserves.

Table 1 shows the set of cases that were examined. Variations were made on the changes to the central system capacity, fuel prices, consumer demand, the amount of production from the DER, and whether the DER's thermal exhaust was used.

Table 1. Scenarios analyzed

\begin{tabular}{|c|c|c|c|c|c|}
\hline \multirow{2}{*}{$\begin{array}{c}\text { System capacity } \\
\text { change }\end{array}$} & \multirow[t]{2}{*}{ Fuel prices } & \multirow[t]{2}{*}{ Demand } & \multirow[t]{2}{*}{ DER mode } & \multicolumn{2}{|c|}{ Scenarios Analyzed } \\
\hline & & & & No CHP & With CHP \\
\hline \multirow{2}{*}{ No cancel } & \multirow{2}{*}{ Platts (Ref) } & \multirow{2}{*}{$2006+10 \%$} & Peaking & $x$ & $x$ \\
\hline & & & Baseload & $x$ & $x$ \\
\hline \multirow{2}{*}{ Cancel 2000 new } & \multirow{2}{*}{ Platts (Ref) } & \multirow{2}{*}{$2006+10 \%$} & Peaking & $x$ & $x$ \\
\hline & & & Baseload & $\mathrm{X}$ & $X$ \\
\hline \multirow{2}{*}{ Retire 2000 old } & \multirow{2}{*}{ Platts (Ref) } & \multirow{2}{*}{$2006+10 \%$} & Peaking & $x$ & $x$ \\
\hline & & & Baseload & $x$ & $\mathrm{X}$ \\
\hline \multirow{2}{*}{ Cancel 2000 new } & \multirow{2}{*}{ STEO (High) } & \multirow{2}{*}{$2006+10 \%$} & Peaking & $x$ & $\mathrm{X}$ \\
\hline & & & Baseload & $x$ & $x$ \\
\hline \multirow{2}{*}{ Cancel 2000 new } & \multirow{2}{*}{ AEO (Low) } & \multirow{2}{*}{$2006+10 \%$} & Peaking & $x$ & $x$ \\
\hline & & & Baseload & $x$ & $x$ \\
\hline Cancel 1000 new & AEO (Low) & $2006+10 \%$ & Peaking & $x$ & $x$ \\
\hline Cancel 511 new & AEO (Low) & $2006+10 \%$ & Peaking & $x$ & $x$ \\
\hline \multirow{2}{*}{ No cancel } & \multirow{2}{*}{ AEO (Low) } & \multirow{2}{*}{$2006+10 \%$} & Peaking & $\mathrm{X}$ & $x$ \\
\hline & & & Baseload & $x$ & $x$ \\
\hline \multirow{2}{*}{ Cancel 2000 new } & \multirow{2}{*}{ Platts (Ref) } & \multirow{2}{*}{2006} & Peaking & $x$ & $x$ \\
\hline & & & Baseload & $x$ & $\mathrm{X}$ \\
\hline
\end{tabular}


From these options, we can see what impact DER has on the system. Does DER displace CC production on a one-for-one basis or are other technologies also affected? What are the net overall emission changes? What influence does fuel price or excess capacity have on the amount and type of capacity displaced? How much does utilization of the exhaust heat in combined heat and power (CHP) applications influence the overall impact? And, given the market as defined in the model, will new or old capacity more likely be affected by the growth of DER? 


\section{PJM market analysis procedure}

To model the impact of DER on an area's power system we first must collect the data to define the system, both supply and demand. More extensive discussion of the methodology can be found in our earlier report on DER benefits (Hadley et al 2003). Appendix A of that report describes the methodology used in modeling the PJM electric system supply and demand and implemented via the ORCED computer code (Hadley and Hirst, 1998).

DER generation can be treated as a reduction in system demands, with consequent changes in the load duration curves. Comparing the changes in production provides information on system response to the addition of DER resources, including which plants change their operations and the consequent change in emissions.

\subsection{PJM System Data}

To quantify the impact of DER on the power system we have to model that power system both with and without the DER in question. For this study, we chose to model the PJM-East power pool, which contains most of Pennsylvania, New Jersey, Maryland, and Delaware (Figure 2). It is also referred to as the MidAtlantic Area Council (MAAC), one of the reliability councils in the North American Electric Reliability Council. The light-green area represents PJM-West which is located in other reliability council regions.

Figure 2. PJM region including all or parts of Pennsylvania, New Jersey, Maryland, and Delaware.

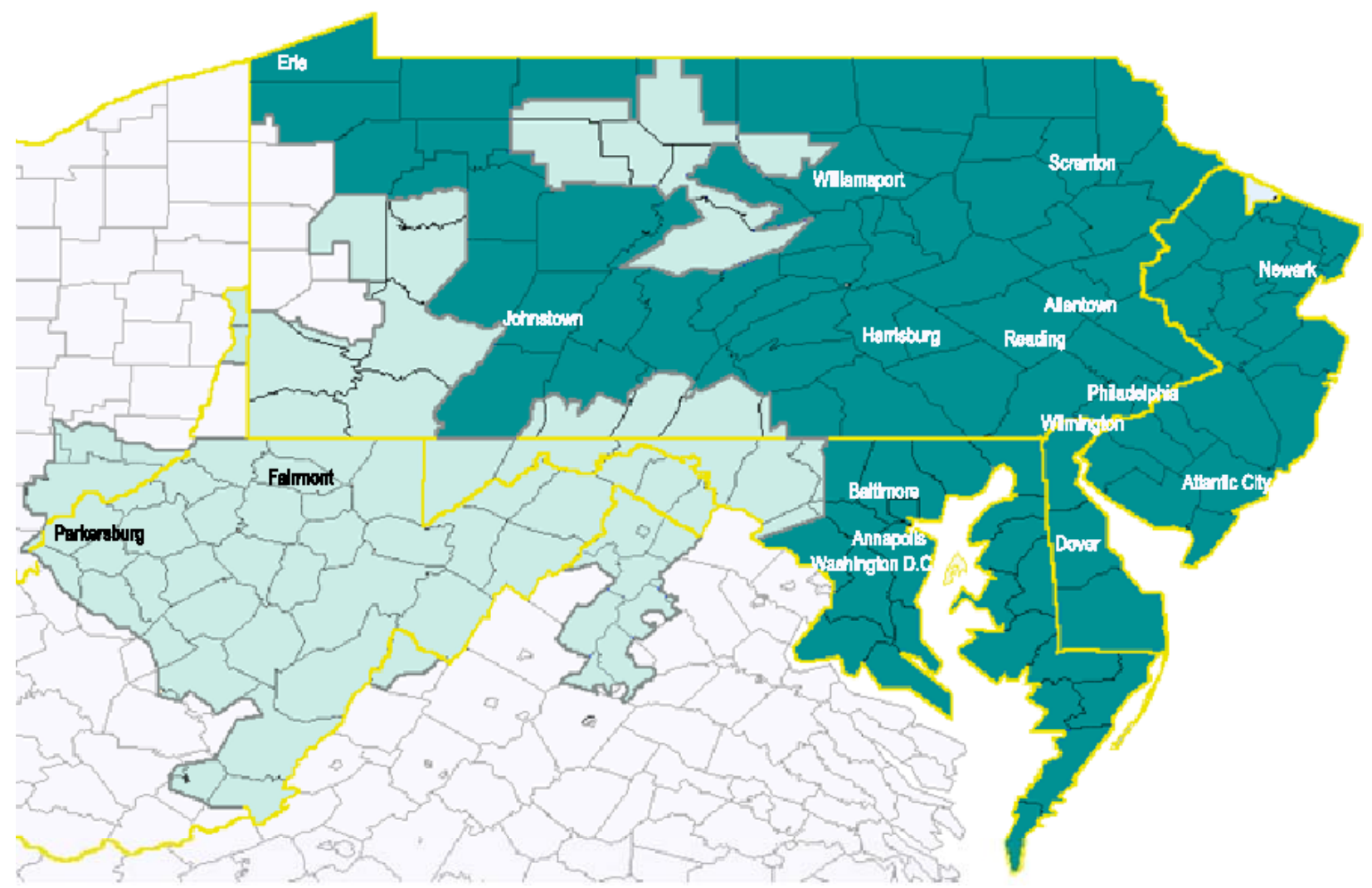

The PJM region has established a wholesale market system that allows power plants and load-serving entities to buy and sell power on an hourly basis. It uses a bidding system to establish real-time prices that are transparent to the market. 
In order to simulate a potentially large amount of DER inclusion in the PJM system, we chose the 2006 time period. Between 2001 and 2006 there is projected to be a relatively large growth in supply (14 GW or $23 \%$ growth from 2001). The amounts in later years are flexible and could be modified in the future if DER were to penetrate. We used the demand data for operation of the system from 1999 and increased it by $11.5 \%$ to represent the expected growth in demand from then until 2006 based on the Annual Energy Outlook 2003 (EIA 2002) plus an additional 10\% to represent growth in sales to other regions. Power plant data for 1999-2001 were used to establish the operating parameters for existing plants. New plants were added based on announced additions.

\subsubsection{PJM Supply}

The operating and emissions characteristics of each plant in the PJM region must be defined. One of the input files from the Energy Information Administration (EIA) National Energy Modeling System lists over 19,000 power plant units nationwide, providing capacity, availability, heat rate, emissions, and date of construction and retirement, among other characteristics. (EIA 2003b) (A power plant may have multiple units, and each unit may be further separated in the database if it has multiple owners.) The power plants in the PJM region that were operating in between 1999 and 2001 were pulled from this database, resulting in a list of 803 units with a combined capacity of over 61,000 MW.

Utilities must submit a large amount of financial and operations information to the Federal Energy Regulatory Commission and the EIA. Platts collects this publicly available information, categorizes it, performs some quality checks on it, and distributes it in a convenient computer program called Powerdat (Platts 2003). The data for the power plants in PJM were pulled from the database. Not all power plants in the EIA dataset are included in the Powerdat database, and some of the data in Powerdat is recorded for the entire plant rather than for individual units. Nevertheless, the data provides additional details, especially on fuel and operating costs for the year.

The new capacity additions that began operation or were planned for 2002 through 2005 were taken from the Platts PowerDat data base (Table 2) (Platts 2003). The ORCED model can include only a limited number of new plants so the capacity for Combined Cycle, and Gas Combustion Turbine (CT) were divided into 18 plants of $661 \mathrm{MW}$ each and 13 plants of $104 \mathrm{MW}$ respectively. They were then brought on line to approximately match the planned capacity for 2002 through 2005 . The costs and performance characteristics for the new plants are not given in the PowerDat database and were assumed based on information in "Cost and Performance Characteristics of New Electricity Generating Technologies" from EIA's publication Assumptions to Annual Energy Outlook 2003. There were only four planned plants that used a fuel other than natural gas, including 2 waste coal plants accounting for about $600 \mathrm{MW}$, a wind turbine plant $(236 \mathrm{MW})$ and a biomass plant of $20 \mathrm{MW}$. Because of their nature, these 4 units were assumed to be "Must Run" plants and do not affect the dispatch of the competitive plants except to the extent that they reduce energy demand that the remaining competitive plants are dispatched to serve.

Table 2. New capacity planned for MAAC region (Platts 2003)

\begin{tabular}{|lrrrrr|}
\hline \multicolumn{1}{|c}{ Type of Capacity } & 2002 & 2003 & 2004 & 2005 & \multicolumn{1}{c|}{$\begin{array}{c}\text { Total Additions } \\
\text { after 2001 }\end{array}$} \\
\hline \hline Combined Cycle & 3305 & 1983 & 2644 & 3966 & 11898 \\
Combustion Turbine & 312 & 1040 & & & 1352 \\
Waste Coal & & & 584 & & 584 \\
Wind & & 236 & & 20 & 236 \\
Biomass & & & & 3986 & 14090 \\
Total & 3617 & 3259 & 3228 & \\
\hline
\end{tabular}


Two further sets of information are available from the Environmental Protection Agency (EPA). It has released a data set for plants used in their Integrated Planning Model (EPA 2002) and in their e-Grid data application (EPA 2001). The files include unit-level data on capacity, heat rate, and emissions rates for $\mathrm{SO}_{2}, \mathrm{NO}_{\mathrm{x}}$, and mercury.

The cost of fuel for each plant is reported in the databases, and the consequent average cost of fuel can be calculated (Table 3). Although the model uses the actual reported cost for each plant, the average provides insight into the general prices paid over these years. These values are shown in Figure 3.

While our main set of scenarios simply used these fuel prices

Table 3. Average fuel prices used in study, $\$ \mathbf{m m B t u}$

\begin{tabular}{|lccc|}
\hline Fuel & $\begin{array}{c}\text { Platts } \\
\text { 1999-2001 }\end{array}$ & $\begin{array}{c}\text { STEO } \\
\mathbf{2 0 0 4}\end{array}$ & $\begin{array}{c}\text { AEO } \\
\mathbf{2 0 0 6}\end{array}$ \\
\hline \hline Gas & 3.87 & 5.63 & 3.25 \\
Oil & 3.08 & 4.53 & 3.84 \\
Coal & 1.30 & 1.19 & 1.41 \\
\hline
\end{tabular}
for the analysis, there were two other sets of fuel prices that were used for sensitivity studies. One set came from the Annual Energy Outlook (AEO) 2003 (EIA 2002), which simulates the energy picture for each region of the country for 2000-2025. It was published in December 2002 based on data available through October of that year, and generally shows prices declining after some high values in the near term. Figure 3 shows the prices that it projects for electric utilities in the MAAC region through 2010. Table 3 shows the prices it lists for 2006.

Figure 3. Fuel prices from EIA's Annual Energy Outlook (AEO), Short-Term Energy Outlook (STEO), and PowerDat database (Platts)

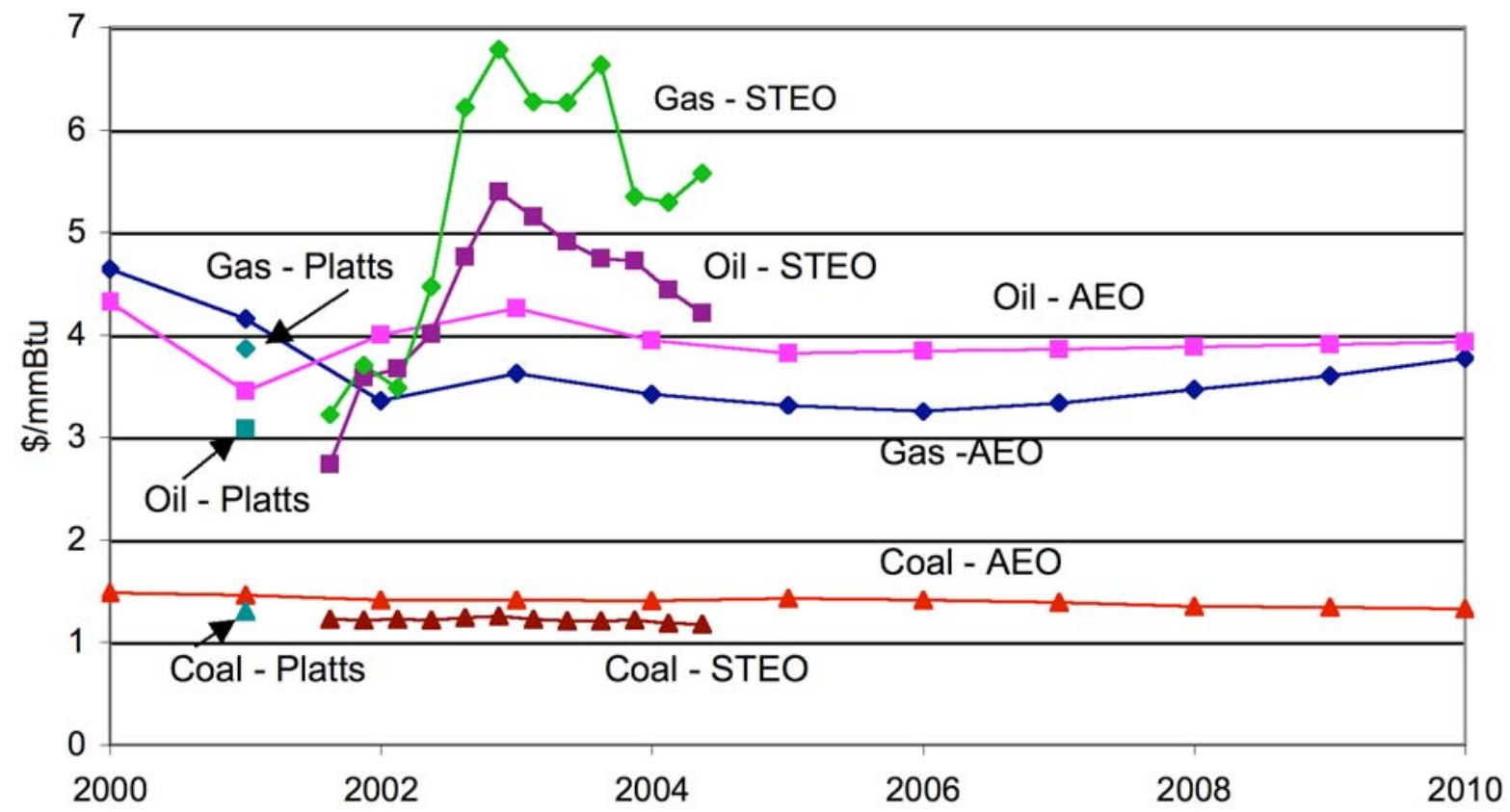

The EIA also publishes a Short Term Energy Outlook (STEO) every month that shows expected prices for the next few years (EIA 2003c). Figure 3 includes the prices from the report from June 2003. Note that these are the national values for the various fuels; the report does not show regional prices as the AEO does. It is notable that in the Platts and STEO results, the gas prices are almost $\$ 0.80$ and $\$ 1.10 / \mathrm{mmBtu}$ higher than the fuel oil prices, but in the AEO the gas prices are lower by $\$ 0.60 / \mathrm{mmBtu}$. This plays a strong role in the relative amounts of gas and oil technologies displaced by DER, as is shown in the sensitivities below. 
Figure 4. PJM supply curve

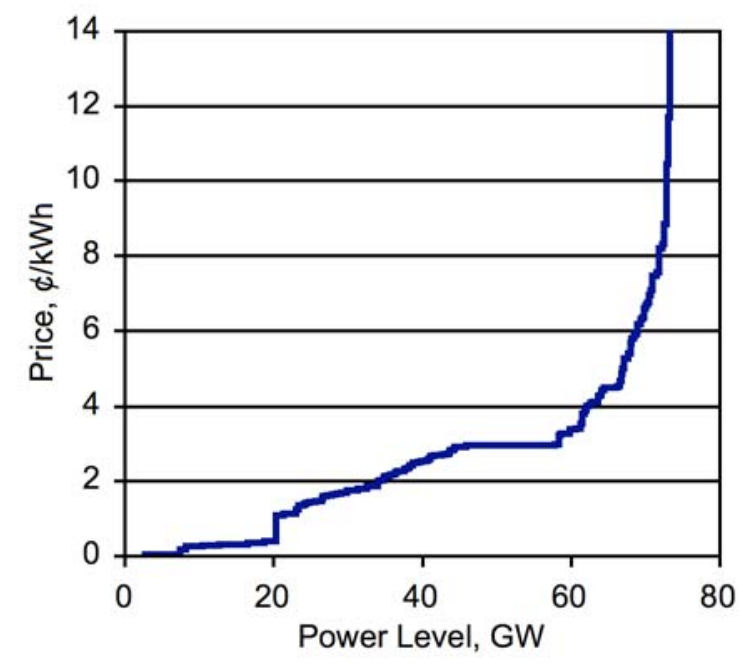

Once the plants were defined, they could be sorted in order of increasing variable cost to create a supply curve for power (Figure 4). The zero price capacity is the non-dispatchable generation, followed by the nuclear capacity at around $0.5 \phi / \mathrm{kWh}$. Coal plants report variable cost from $\sim 1.5$ to $3 \notin / \mathrm{kWh}$. Oil and gas plants have variable prices from $\sim 2.5$ to $16 \notin / \mathrm{kWh}$ and beyond. The new combined cycle plants had variable costs of $3 \phi / \mathrm{kWh}$ and can be seen in the figure as a straight segment between 40 and $60 \mathrm{GW}$. The new combustion turbines had a variable cost of $4.5 \phi / \mathrm{kWh}$ plus up to $4 \phi / \mathrm{kWh}$ to cover start-up costs depending how infrequently they were called upon.

\subsubsection{PJM Demand}

The other key factor in determining power plant production is defining the demands on the grid. PJM reports their hourly demands, both current and historical, on their website (PJM 2002). Figure 5 shows the hourly change in demands over the year 1999. Note that the highest demands occur in the summertime, due to the air conditioning requirements. Therefore, a peak season between May 1 and September 30 was selected because $\mathrm{NO}_{\mathrm{X}}$ emissions are more heavily regulated in the region during this time. Using this definition allows us to gather more detailed information specific to that season. This hourly data is used to produce an LDC for the peak and off-peak seasons.

\section{Figure 5. PJM hourly system demand for 1999}

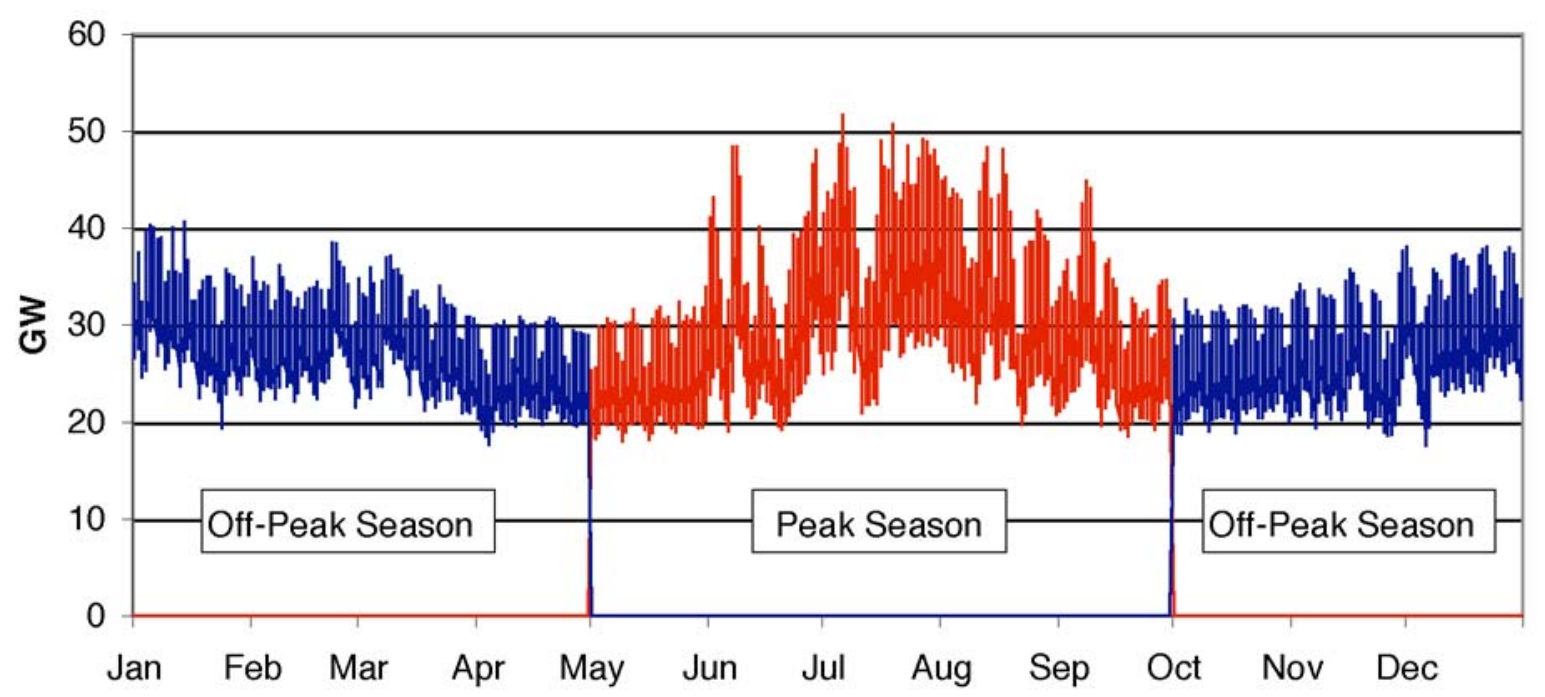

In this Phase III study, we increased demand in each hour by $11.5 \%$ from the values in 1999 to approximate a demand curve for 2006. However, with the expected growth in supplies (above), a growth of only $11.5 \%$ resulted in a large overcapacity for the region. To overcome this, we assumed a further $10 \%$ growth in demand by sales to other regions of the country. This resulted in a peak demand of 62,500 MW and reserve margin of $18 \%$. Sensitivities were run to evaluate the impact of lower demands and consequent higher reserve margins. 
With supply and demand for the no DER case established, the plants can be dispatched and marginal plants determined. Figure 6 shows the dispatch of plants for the peak season by type of plant, and Figure 7 shows the plants for the off-peak season. Note that the large block of gas-fired plants are the plants added between 2001 and 2005. They all are modeled to have the same operating costs so stay together during the dispatch. Some are only dispatched a small percentage of the year, because of their relative fuel cost and the amount of reserves.

Figure 6. Plants dispatched during the peak season by fuel type

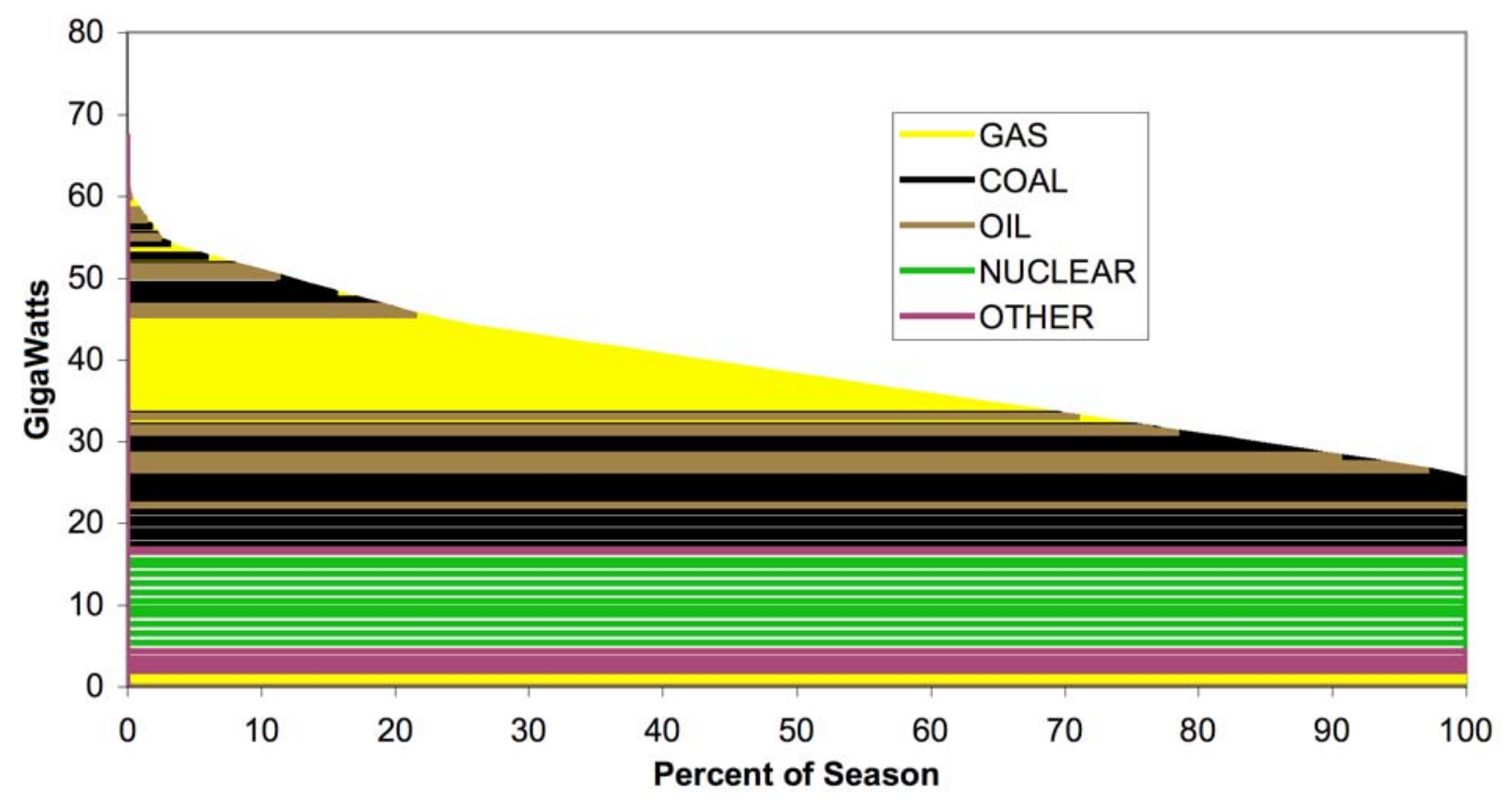

Figure 7. Plants dispatched during the off-peak season by fuel type

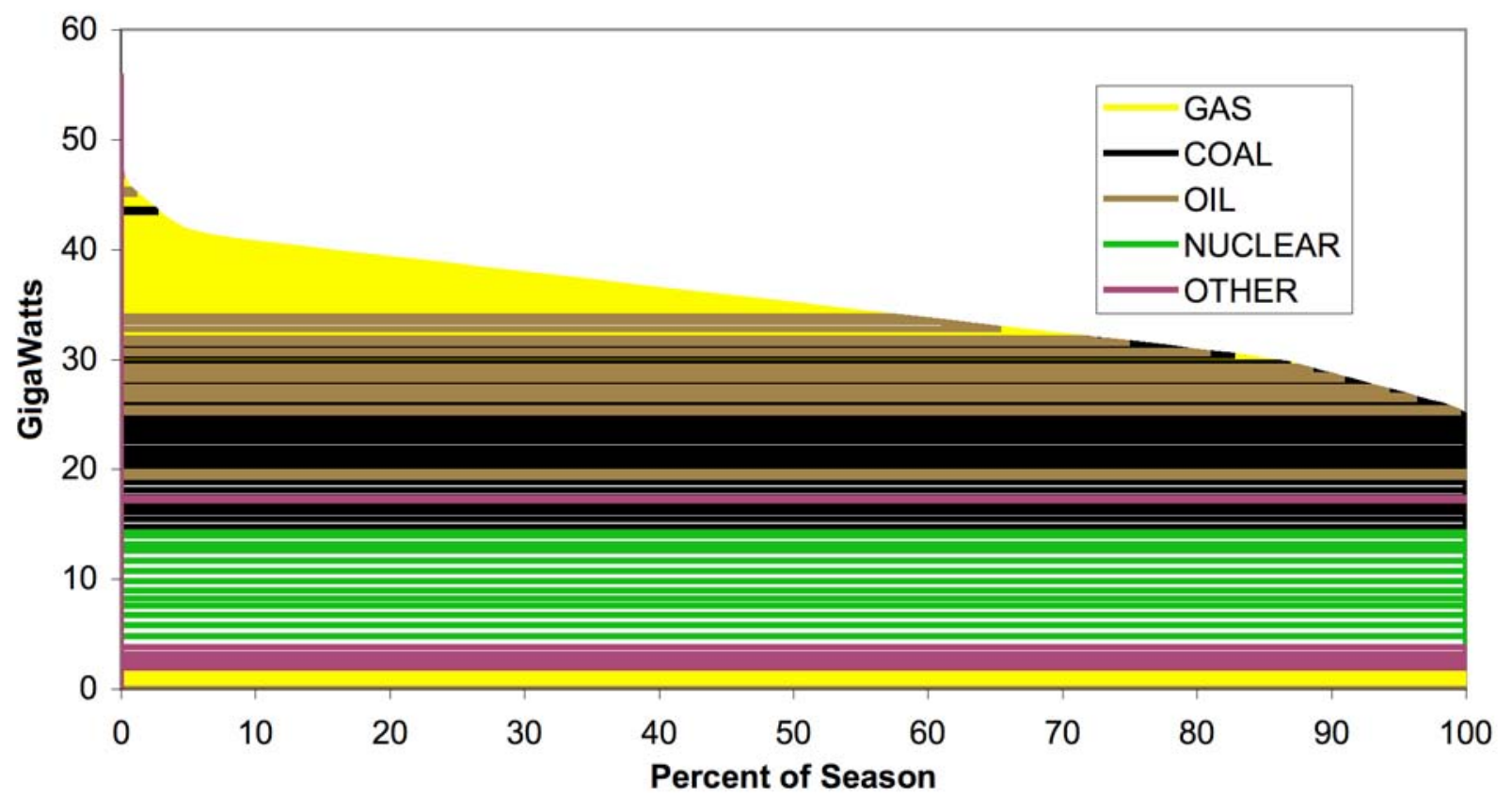




\subsection{DER additions}

To examine the impact of large amounts of DER added to the system, we hypothesized $2000 \mathrm{MW}$ of DER capacity added. With capacity increasing by 14,000 MW in our analysis, this is below the long-term goal of $20 \%$ of new capacity coming from DER, but is still more than likely will be developed by 2006 . Two scenarios were run: one with $2000 \mathrm{MW}$ of DER running all the time (Baseload), and one with $2000 \mathrm{MW}$ of DER running from 8 am to $8 \mathrm{pm}$ on weekdays (Peaking). Actual DER operations would be more complex than this. The Baseload DER system would have some downtime at different times of the year that would lower its capacity, while the Peaking DER would have some fraction operating at earlier or later times, or on weekends.

Figure 8. Annual LDCs with no DER, Peaking DER, The Baseload scenario simply had the and Baseload DER removed from demand

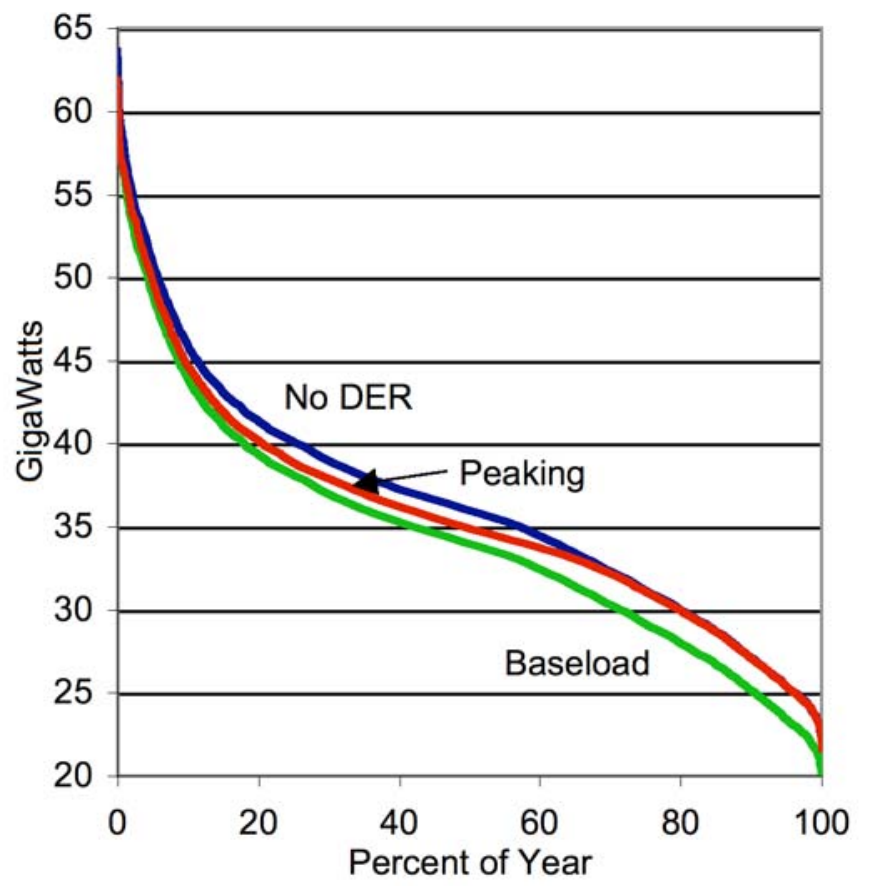
demands on the system for every hour drop by 2000 MW (Figure 8). The LDC was lowered at all points. The Peaking scenario had a more complex impact on the LDC because it only lowered demand in certain hours. The annual system peak only dropped $510 \mathrm{MW}$ instead of 2000 MW because system peak demands during weekends were not affected.

The DER used for the analysis was a low $\mathrm{NO}_{\mathrm{X}}$ CT used in the Phase II analysis. Its characteristics are shown in Table 4, along with pertinent parameters of the new combined cycle plants (EIA 2003a) and existing non-electrical boilers, also from the Phase II study. The Solar Mars 90 is a 9.5 MW turbine with dry Low- $\mathrm{NO}_{\mathrm{X}}$ combustion and $5 \mathrm{ppm} \mathrm{NO}_{\mathrm{X}} \mathrm{SCR}$. With an electrical efficiency of $29 \%$ and a heat exchanger efficiency of $62 \%$, the total efficiency of the DER is $73 \%$.

If the exhaust heat from the DER is used for thermal energy at the facility where it is located, then the DER can replace some or all of the existing thermal needs of the site. This reduces or removes the need for boilers, chillers, or other equipment for process heat. To analyze the change in energy and emissions if CHP is used, we modeled the displaced thermal source as a boiler with the characteristics shown in Table 4.

Both the DER and the $\mathrm{CC}$ facility are modeled as low- $\mathrm{NO}_{\mathrm{X}}$ emitters, while the thermal boiler modeled has emissions based on the average value for gas-fired steam turbine-boilers (ST) in the region, as in the Phase II study. Typically, $\mathrm{NO}_{\mathrm{X}}$ emissions are reported in terms of $\mathrm{lb} / \mathrm{mmBtu}$ of thermal energy in. In Table 4, we also calculate the emissions in terms of $\mathrm{lb} / \mathrm{mmBtu}$ of useful energy out. For the new CC, the value is the amount in divided by its electrical efficiency while for the boiler the value is the amount in divided by its heat exchanger or thermal efficiency. However, the DER in CHP mode creates both electrical and thermal output and its emissions are the input amount divided by its combined efficiency of $73 \%$. Similarly, since all three technologies use natural gas, they have the same $\mathrm{CO}_{2}$ emissions based on input energy. However, based on useful energy out, the DER is the least polluting. 
Table 4. Distributed generation (with CHP) and alternative technologies

\begin{tabular}{|c|c|c|c|c|c|c|c|c|}
\hline \multirow[t]{2}{*}{ Model/Type } & \multirow[t]{2}{*}{$\begin{array}{c}\text { Capital } \\
\text { Cost, } \$ / k W\end{array}$} & \multirow[t]{2}{*}{$\begin{array}{l}\text { O\&M } \\
\text { Cost, } \\
\text { \$/MWh }\end{array}$} & \multirow[t]{2}{*}{$\begin{array}{l}\text { Electrical } \\
\text { Efficiency }\end{array}$} & \multirow[t]{2}{*}{$\begin{array}{c}\text { Heat } \\
\text { Exchanger } \\
\text { Efficiency }\end{array}$} & \multicolumn{2}{|c|}{$\begin{array}{c}\mathrm{NO}_{\mathrm{x}} \\
\text { emissions, } \\
\text { Ib/mmBtu }\end{array}$} & \multicolumn{2}{|c|}{$\begin{array}{c}\mathrm{CO}_{2} \\
\text { emissions, } \\
\text { lb/mmBtu }\end{array}$} \\
\hline & & & & & In & Out & In & Out \\
\hline Solar Mars 90 & 785 & 15 & $29 \%$ & $62 \%$ & 0.022 & 0.030 & 117 & 160 \\
\hline New Gas CC & 536 & $2.0^{*}$ & $49 \%$ & - & 0.02 & 0.041 & 117 & 240 \\
\hline Non-electric Boiler & & & - & $72 \%$ & 0.23 & 0.32 & 117 & 162 \\
\hline
\end{tabular}

* Plus $\$ 12 / \mathrm{kw}$-yr fixed O\&M cost

Source: Iannucci 2002, EIA 2003

Given that adding DER does not necessarily mean displacing an equal amount of CC, the actual changes in emissions will be different than shown in the table. If the DER displaces higher emitting sources then of course the reduction in emissions will be greater. 


\section{Analysis}

Once the supplies and demands were defined then a set of cases were run using ORCED. As mentioned above, there are three extremes of possible responses to the addition of DER: no change in central system capacity, new plants are cancelled before construction, or old plants are retired. The actual response may be a mix of these scenarios, but evaluating these will show the range of impacts on the central grid.

\subsection{DER adds to reserve margin}

The first set of cases assumed that even though the DER was installed, no new plants were cancelled or older plants retired. Instead the reserve margin increased from $18 \%$ to $19 \%$ in the Baseload DER scenario and $22 \%$ in the Peaking DER scenario. This scenario is similar to the analysis carried out in the Phase II report, but with higher levels of DER.

\section{Figure 9. Generation displaced by DER if no central capacity cancelled or retired}

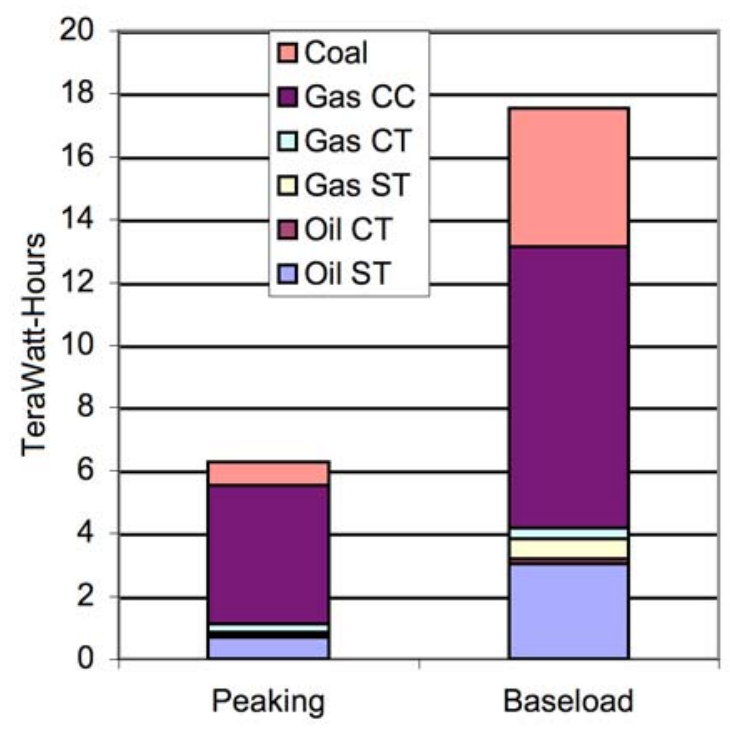

Table 5. Generation displaced by DER if no central capacity cancelled or retired (GWh)

\begin{tabular}{|l|rr|rr|}
\hline Plant Type & \multicolumn{2}{c}{ Peaking } & \multicolumn{2}{c|}{ Baseload } \\
\hline \hline Coal & 744 & $12 \%$ & 4383 & $25 \%$ \\
Gas CC & 4413 & $70 \%$ & 8985 & $51 \%$ \\
Gas CT & 263 & $4 \%$ & 344 & $2 \%$ \\
Gas ST & 85 & $1 \%$ & 619 & $4 \%$ \\
Oil CT & 59 & $1 \%$ & 168 & $1 \%$ \\
Oil ST & 699 & $11 \%$ & 3021 & $17 \%$ \\
\hline Total & 6264 & $100 \%$ & 17520 & $100 \%$ \\
\hline
\end{tabular}

Table 6. Energy and emissions parameters of displaced generation

\begin{tabular}{|lcc|}
\hline & Peaking & Baseload \\
\hline \hline Avg Displaced Efficiency & $40 \%$ & $38 \%$ \\
$\mathrm{CO}_{2}, \mathrm{lb} / \mathrm{MWh}$ & 1194 & 1423 \\
$\mathrm{NO}_{x}, \mathrm{lb} / \mathrm{MWh}$ & 1.14 & 1.87 \\
$\mathrm{SO}_{2}, \mathrm{lb} / \mathrm{MWh}$ & 3.41 & 6.78 \\
\hline
\end{tabular}

Figure 9 and Table 5 show the different central generating technologies that get displaced by the added DER. Although the same amount of capacity was available, the plants did not run for as much of the year; the plant on the margin at any point in time was the plant that is reduced. Gas CC made up a significant portion of the displaced power, but not all of it. In the Baseload scenario especially, coal and oil-fired steam generation was also displaced.

The large amount of CC capacity on the margin means that average electrical efficiency was relatively high $(38 \%-40 \%)$ compared to the electricity efficiency of the DER $(29 \%)$ that displaced it (Table 6). Replacing the lost generation with DER changed the amount of primary energy and emissions used to provide the energy services. Without CHP, only electricity services were replaced. With CHP, some amount of other thermal energy needs was replaced by the exhaust from the DER. Table 7 shows the changes in energy and major air pollutants. The central generation displaced by the DER was more efficient so the total primary energy for electricity generation was higher. However, if the thermal energy from the DER is used, the net energy use declined. $\mathrm{CO}_{2}$ emissions reflect these same factors, with emissions higher with DER if CHP displacement is not included. However, $\mathrm{NO}_{\mathrm{X}}$ and $\mathrm{SO}_{2}$ emissions declined with the use of DER even without CHP. Despite the high amount of CC that was displaced, the 
total central generation displaced had higher emissions than DER. Including the emissions displaced from the thermal sources by CHP made the savings even higher.

Table 7. Primary energy use, $\mathrm{CO}_{2}, \mathrm{NO}_{\mathrm{x}}$, and $\mathrm{SO}_{2}$ emissions from $2000 \mathrm{MW}$ of Combustion Turbine$6 \mathrm{~B}$ with and without $\mathrm{CHP}$ if no generation is cancelled or retired

\begin{tabular}{|l|l|rrrrr|}
\hline \multicolumn{2}{|c|}{} & Dist. Gen. & $\begin{array}{c}\text { Electric } \\
\text { System }\end{array}$ & $\begin{array}{c}\text { Net w/o } \\
\text { CHP }\end{array}$ & $\begin{array}{c}\text { Thermal } \\
\text { System }\end{array}$ & Net w/ CHP \\
\hline \hline Primary Energy, & Peaking DER & 74 & -53 & 21 & -46 & -24 \\
& Bastu & 208 & -159 & 49 & -128 & -79 \\
\hline $\mathbf{C O}_{2}$, MTons & Peaking DER & 4.4 & -3.7 & 0.6 & -2.7 & -2.1 \\
& Baseload DER & 20.8 & -15.9 & 4.9 & -12.8 & -7.9 \\
\hline NO $_{\mathbf{x}}$, kTons & Peaking DER & 0.8 & -3.6 & -2.8 & -10.5 & -13.3 \\
& Baseload DER & 2.3 & -16.4 & -14.1 & -29.4 & -43.5 \\
\hline $\mathbf{S O}_{2}$, kTons & Peaking DER & 0.0 & -10.7 & -10.7 & 0.0 & -10.7 \\
& Baseload DER & 0.0 & -59.4 & -59.4 & 0.0 & -59.4 \\
\hline
\end{tabular}

\subsection{DER displaces new capacity}

The next set of scenarios involved removing $2000 \mathrm{MW}$ of new CC capacity from the ORCED runs with DER. This changed the reserve margin in the baseload scenario to $18.7 \%$ (from the reference case of $18.1 \%$ ) while the Peaking scenario reserve margin dropped to $15.8 \%$. This latter reduction is because the annual peak demand did not drop 2000 MW but only 511 MW since the DER did not change the weekend peaks.

Surprisingly, the relative amounts of displaced generation did not change significantly in the Baseload scenario with the cancellation of the CC; CC displacement increased from $51 \%$ to $60 \%$ of the DER production, with consequent reductions in the other technologies (Figure 10). The normal thought would be that the DER would displace only CC production since the equivalent capacity was cancelled. Instead, at some times of the year other technologies were on the margin and so were reduced. In the Baseload scenario the DER was run at effectively $100 \%$ capacity factor, so even if the cancelled CC had operated at its full availability of $86 \%$, then other technologies would have been called upon to reduce their production. In the reference case, furthermore, the new $\mathrm{CC}$ had a marginal cost of $2.93 \phi / \mathrm{kWh}$ which made it more of an intermediate producer, operating with a capacity factor between $60 \%$ and $15 \%$, depending on the plant.

In the Peaking scenario, the cancellation of new CC meant that almost all of the DER generation displaced possible CC generation. However, small amounts of other generation were also displaced and CT generation actually increased slightly to make up for the loss of CC capacity during peak times (Table 8 ). The DER capacity more nearly aligned with the capacity of the cancelled production. 
Figure 10. Generation displaced by DER if $2000 \mathrm{MW}$ of CC capacity is cancelled compared to if no capacity is cancelled

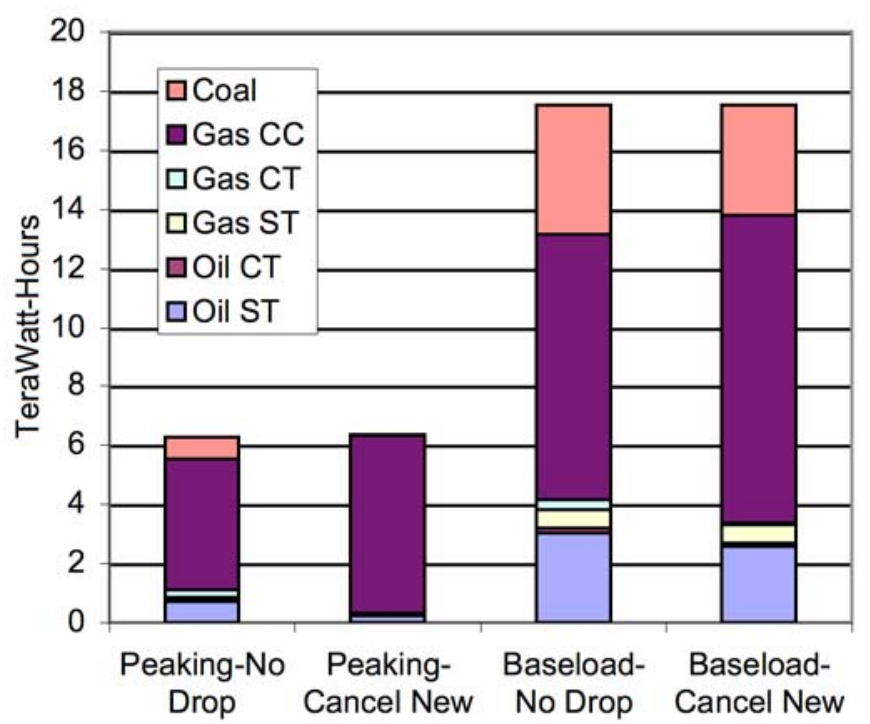

Table 8. Generation displaced by DER if $2000 \mathrm{MW}$ of $\mathrm{CC}$ capacity is cancelled (GWh)

\begin{tabular}{|l|rr|rr|}
\hline Plant Type & \multicolumn{2}{|c}{ Peaking } & \multicolumn{2}{c|}{ Baseload } \\
\hline \hline Coal & 39 & $1 \%$ & 3720 & $21 \%$ \\
Gas CC & 6009 & $96 \%$ & 10452 & $60 \%$ \\
Gas CT & -84 & $-1 \%$ & 47 & $0 \%$ \\
Gas ST & 65 & $1 \%$ & 607 & $3 \%$ \\
Oil CT & 15 & $0 \%$ & 130 & $1 \%$ \\
Oil ST & 219 & $4 \%$ & 2564 & $15 \%$ \\
\hline Total & 6264 & $100 \%$ & 17520 & $100 \%$ \\
\hline
\end{tabular}

As with the first set of cases, primary energy use and $\mathrm{CO}_{2}$ emissions increased with DER used only for electricity, but decreased if CHP was used (Table 9). $\mathrm{SO}_{2}$ and $\mathrm{NO}_{\mathrm{X}}$ emissions declined even from the electricity generation because of the low emissions from DER, except for $\mathrm{NO}_{\mathrm{X}}$ in the Peaking scenario. In that case, the low $\mathrm{NO}_{\mathrm{X}}$ emissions from $\mathrm{CC}$ mean that net emissions without CHP were higher with DER.

Table 9. Primary energy use, $\mathrm{CO}_{2}, \mathrm{NO}_{\mathrm{x}}$, and $\mathrm{SO}_{2}$ emissions from $2000 \mathrm{MW}$ of Combustion Turbine$6 \mathrm{~B}$ with and without $\mathrm{CHP}$ if $2000 \mathrm{MW}$ of $\mathrm{CC}$ capacity is cancelled

\begin{tabular}{|c|c|c|c|c|c|c|}
\hline & & Dist. Gen. & $\begin{array}{l}\text { Electric } \\
\text { System }\end{array}$ & $\begin{array}{c}\text { Net w/o } \\
\text { CHP }\end{array}$ & $\begin{array}{l}\text { Thermal } \\
\text { System }\end{array}$ & Net w/ CHP \\
\hline $\begin{array}{l}\text { Primary Energy, } \\
\text { TBtu }\end{array}$ & $\begin{array}{l}\text { Peaking DER } \\
\text { Baseload DER }\end{array}$ & $\begin{array}{r}74 \\
208\end{array}$ & $\begin{array}{r}-45 \\
-152\end{array}$ & $\begin{array}{l}30 \\
57\end{array}$ & $\begin{array}{r}-46 \\
-128\end{array}$ & $\begin{array}{l}-16 \\
-71\end{array}$ \\
\hline $\mathrm{CO}_{2}$, MTons & $\begin{array}{l}\text { Peaking DER } \\
\text { Baseload DER }\end{array}$ & $\begin{array}{r}4.4 \\
20.8\end{array}$ & $\begin{array}{r}-2.7 \\
-15.2\end{array}$ & $\begin{array}{l}1.6 \\
5.7\end{array}$ & $\begin{array}{r}-2.7 \\
-12.8\end{array}$ & $\begin{array}{l}-1.0 \\
-7.1\end{array}$ \\
\hline $\mathrm{NO}_{\mathrm{x}}$, kTons & \begin{tabular}{|l|} 
Peaking DER \\
Baseload DER
\end{tabular} & $\begin{array}{l}0.8 \\
2.3\end{array}$ & $\begin{array}{r}-0.7 \\
-13.7 \\
\end{array}$ & $\begin{array}{r}0.1 \\
-11.4 \\
\end{array}$ & $\begin{array}{l}-10.5 \\
-29.4\end{array}$ & $\begin{array}{l}-10.4 \\
-40.8 \\
\end{array}$ \\
\hline $\mathrm{SO}_{2}$, kTons & \begin{tabular}{|l|} 
Peaking DER \\
Baseload DER
\end{tabular} & $\begin{array}{l}0.0 \\
0.0\end{array}$ & $\begin{array}{r}-1.6 \\
-50.7\end{array}$ & $\begin{array}{r}-1.6 \\
-50.7\end{array}$ & $\begin{array}{l}0.0 \\
0.0\end{array}$ & $\begin{array}{r}-1.6 \\
-50.7\end{array}$ \\
\hline
\end{tabular}

\subsection{DER accelerates retirements}

For various reasons, it may be that instead of causing cancellations of new plants, the addition of DER will encourage the retirement of older plants. It may be that the older plants are very inefficient or polluting, such that it is more cost-effective to replace them with new capacity (new CC or DER.) Alternatively, the new plants and old plants may be owned by different groups with different motivations for continuing (or discontinuing) their operation. As an example, Reliant Energy has recently announced the mothballing of some of their peaking and intermediate plants in the mid-Atlantic region due to low sales (Reuters 2003).

To explore this, we examined the finance and operations of the central plants in the scenario with no plants retired (section 3.1) to find which existing plants had the highest avoidable losses per unit of available capacity. The losses were defined as the revenues minus the out-of-pocket costs, including the variable costs such as fuel and the fixed and variable O\&M costs, but not including sunk capital costs 
such as depreciation. We then retired the first $2000 \mathrm{MW}$, which included 1,475 MW of oil capacity, 300 MW of coal, and 225 of gas.

Figure 11. Generation displaced by DER if $2000 \mathrm{MW}$ of existing capacity is retired compared to if no capacity retired

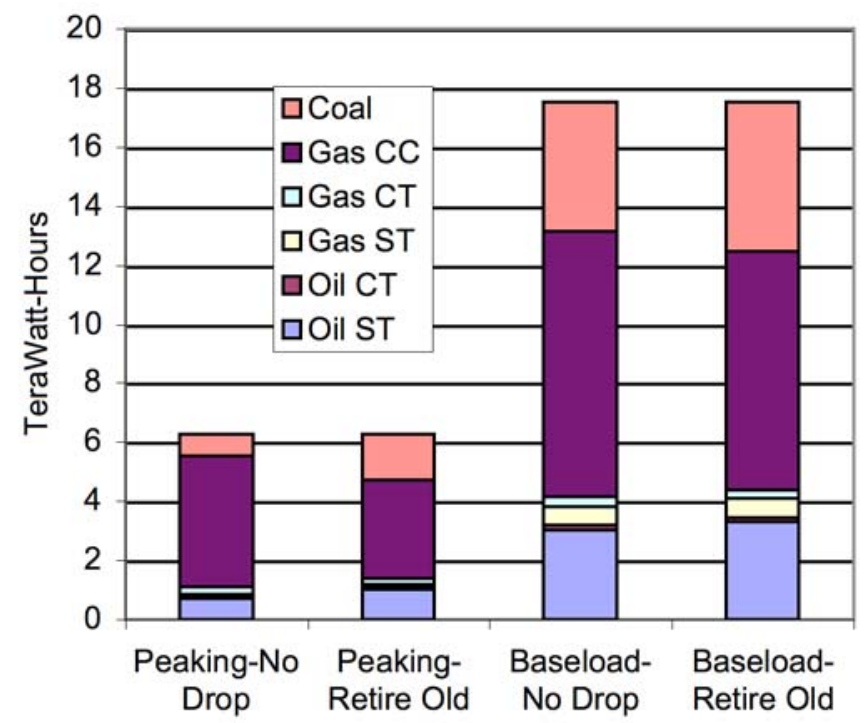

Table 10. Generation displaced by DER if 2000 MW of existing capacity is retired (GWh)

\begin{tabular}{|l|rr|rr|}
\hline Plant Type & \multicolumn{2}{c}{ Peak } & \multicolumn{2}{c|}{ Baseload } \\
\hline \hline Coal & 1543 & $25 \%$ & 5052 & $29 \%$ \\
Gas CC & 3342 & $53 \%$ & 8099 & $46 \%$ \\
Gas CT & 196 & $3 \%$ & 283 & $2 \%$ \\
Gas ST & 108 & $2 \%$ & 641 & $4 \%$ \\
Oil CT & 48 & $1 \%$ & 158 & $1 \%$ \\
Oil ST & 1027 & $16 \%$ & 3287 & $19 \%$ \\
\hline Total & 6264 & $100 \%$ & 17520 & $100 \%$ \\
\hline
\end{tabular}

After retiring these plants, we ran the Peaking and Baseload DER scenarios (Figure 11 and Table 10). As would be expected, oil and coal technologies had larger displacement than in the other scenarios. Their generation declined because of the addition of DER and concomitant retirement of their capacity.

The retirement of older, more inefficient capacity meant that the DER had a more positive impact on the environment (Table 11). While primary energy was still higher with the DER before $\mathrm{CHP}$, the $\mathrm{CO}_{2}$ emissions were less in the Peaking scenario because of the inefficiency and fuel type of the displaced energy.

Table 11. Primary energy use, $\mathrm{CO}_{2}, \mathrm{NO}_{\mathrm{x}}$, and $\mathrm{SO}_{2}$ emissions from $2000 \mathrm{MW}$ of Combustion Turbine-6B with and without CHP if $2000 \mathrm{MW}$ of existing capacity is retired

\begin{tabular}{|l|l|rrrrr|}
\hline \multicolumn{2}{|c|}{} & Dist. Gen. & $\begin{array}{c}\text { Electric } \\
\text { System }\end{array}$ & $\begin{array}{c}\text { Net w/o } \\
\text { CHP }\end{array}$ & $\begin{array}{c}\text { Thermal } \\
\text { System }\end{array}$ & Net w/ CHP \\
\hline \hline Primary Energy, & Peaking DER & 74 & -57 & 18 & -46 & -28 \\
TBtu & Baseload DER & 208 & -162 & 46 & -128 & -82 \\
\hline $\mathbf{C O}_{2}$, Mtons & Peaking DER & 4.4 & -4.4 & -0.1 & -2.7 & -2.7 \\
& Baseload DER & 20.8 & -16.2 & 4.6 & -12.8 & -8.2 \\
\hline NO $_{\mathbf{x}}, \mathbf{k T o n s}$ & Peaking DER & 0.8 & -6.0 & -5.2 & -10.5 & -15.7 \\
& Baseload DER & 2.3 & -18.4 & -16.1 & -29.4 & -45.5 \\
\hline $\mathbf{S O}_{2}, \mathbf{k T O n s}$ & Peaking DER & 0.0 & -12.9 & -12.9 & 0.0 & -12.9 \\
& Baseload DER & 0.0 & -61.1 & -61.1 & 0.0 & -61.1 \\
\hline
\end{tabular}

\subsection{Sensitivities}

Two large uncertainties exist in modeling future electricity markets: fuel prices and the relative supply and demand for power. The reference scenarios above used fuel prices based on data for PJM between 1999 and 2001. Other recent forecasts give prices that are higher and lower than those values. Separately, our reference scenario adjusted supplies and demands to achieve reserve margins that are more typical over the long-term. However, recent activity in the market has created a temporary glut in capacity. How quickly this overcapacity will come into balance and how it will do so is not known. We chose to run one 
sensitivity with the original amounts of capacity and demands for 2006 (without the assumption of $10 \%$ increase for exports) to see how this would impact displacement by DER.

\subsubsection{High gas prices}

The EIA publishes their Short-Term Energy Outlook (STEO) on a monthly basis. It gives quarterly price projection for the next several years, and is generally more accurate than the long-term forecasts that are available from the Annual Energy Outlook. Recent changes in the gas market especially have caused great volatility in prices (Figure 3). The forecast oil and gas prices for 2004 are roughly $\$ 1.5 / \mathrm{mmBtu}$ higher than the average prices based on the Platts data for 1999-2001 (Table 3).

Figure 12. Generation displaced with new CC capacity cancelled and reference (Platts) and high (STEO) gas prices

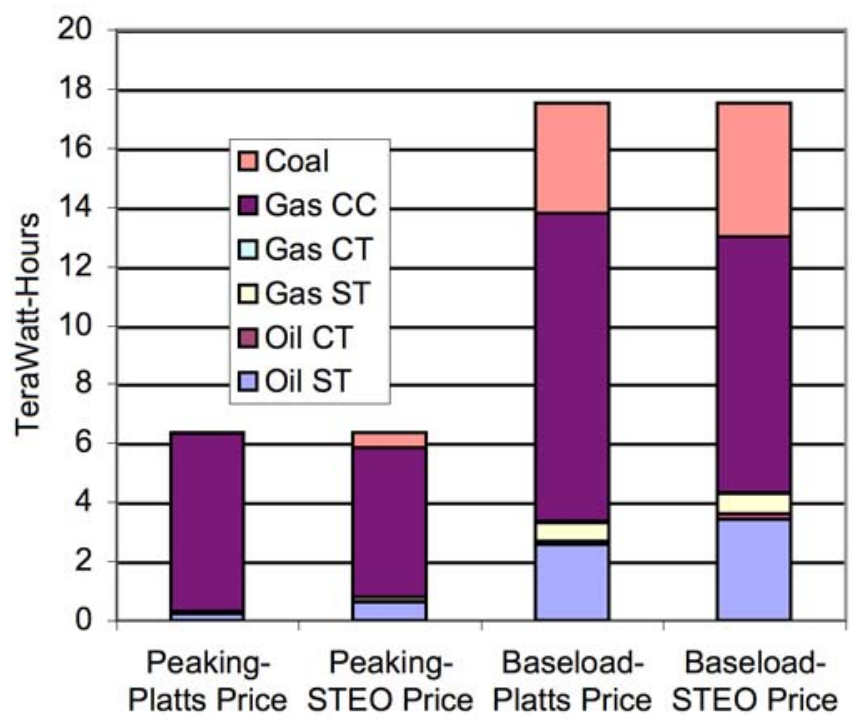

Table 12. Generation displaced with capacity cancelled and high (STEO) gas prices (GWh)

\begin{tabular}{|l|rr|rr|}
\hline Plant Type & \multicolumn{2}{c}{ Peak } & \multicolumn{2}{c|}{ Baseload } \\
\hline \hline Coal & 506 & $8 \%$ & 4510 & $26 \%$ \\
Gas CC & 5031 & $80 \%$ & 8694 & $50 \%$ \\
Gas CT & -70 & $-1 \%$ & 41 & $0 \%$ \\
Gas ST & 140 & $2 \%$ & 678 & $4 \%$ \\
Oil CT & 33 & $1 \%$ & 184 & $1 \%$ \\
Oil ST & 624 & $10 \%$ & 3413 & $19 \%$ \\
\hline Total & 6264 & $100 \%$ & 17520 & $100 \%$ \\
\hline
\end{tabular}

With the oil and gas prices higher than the base case, the main beneficiary was the coal production. Without any change due to DER, coal-fired generation increased by $9 \%$ while oil decreased by $9 \%$ and gas by $18 \%$. Consequently, while the DER displaced gas CC (because of the $2000 \mathrm{MW}$ of

cancellations), coal and oil production was also on the margin and so was reduced.

Because of the displacement of coal and oil by DER, $\mathrm{NO}_{\mathrm{X}}$ and $\mathrm{SO}_{2}$ emissions declined with the use of DER, even just considering the electricity generation (Table 13). With the added savings from thermal system reductions, energy and $\mathrm{CO}_{2}$ were reduced as well.

Table 13. Primary energy use, $\mathrm{CO}_{2}, \mathrm{NO}_{\mathrm{x}}$, and $\mathrm{SO}_{2}$ emissions from $2000 \mathrm{MW}$ of CT-6B with and without CHP if $2000 \mathrm{MW}$ of new CC capacity is cancelled and gas prices are higher

\begin{tabular}{|l|l|rrrrr|}
\hline \multicolumn{2}{|c|}{} & Dist. Gen. & $\begin{array}{r}\text { Electric } \\
\text { System }\end{array}$ & $\begin{array}{c}\text { Net w/o } \\
\text { CHP }\end{array}$ & $\begin{array}{c}\text { Thermal } \\
\text { System }\end{array}$ & Net w/ CHP \\
\hline \hline Primary Energy, & Peaking DER & 74 & -49 & 26 & -46 & -20 \\
& Batu & 208 & -158 & 50 & -128 & -78 \\
\hline $\mathbf{C O}_{2}$, Mtons & Peaking DER & 4.4 & -3.3 & 1.0 & -2.7 & -1.6 \\
& Baseload DER & 20.8 & -15.8 & 5.0 & -12.8 & -7.8 \\
\hline NO $_{\mathbf{x}}, \mathbf{k T o n s}$ & Peaking DER & 0.8 & -2.6 & -1.8 & -10.5 & -12.3 \\
& Baseload DER & 2.3 & -17.3 & -15.0 & -29.4 & -44.4 \\
\hline SO $_{2}$, kTons & Peaking DER & 0.0 & -7.9 & -7.9 & 0.0 & -7.9 \\
& Baseload DER & 0.0 & -63.9 & -63.9 & 0.0 & -63.9 \\
\hline
\end{tabular}




\subsubsection{Low gas prices}

With gas prices lower than oil prices, the dispatch order will change so that gas-fired plants run more often. In these cases, cancelled gas-fired capacity can have a more significant impact. If the cancelled capacity would have run more than the DER that replaces it, then other technologies will have to run more to make up the difference. This occurred a little in the Peaking scenario using the reference fuel prices (section 3.2), but with lower gas prices is more pronounced.

The AEO 2003 has gas prices for electric utilities in the Mid-Atlantic region (New York, New Jersey, and Pennsylvania) $60 \notin / \mathrm{mmBtu}$ lower than residual oil prices in 2006 (\$3.25 versus \$3.85) (Figure 3). These are opposite what the Platts data and the STEO show in the nearer term. Using these prices, the new CC capacity operated approximately $49 \%$ of the year, which was higher than the $36 \%$ of the year that the peaking DER operates. As a consequence, the other technologies increased their operation (Table 14 and Figure 13). In the Baseload scenario, the DER production was greater than the lost CC production and so other technologies also reduced their operations.
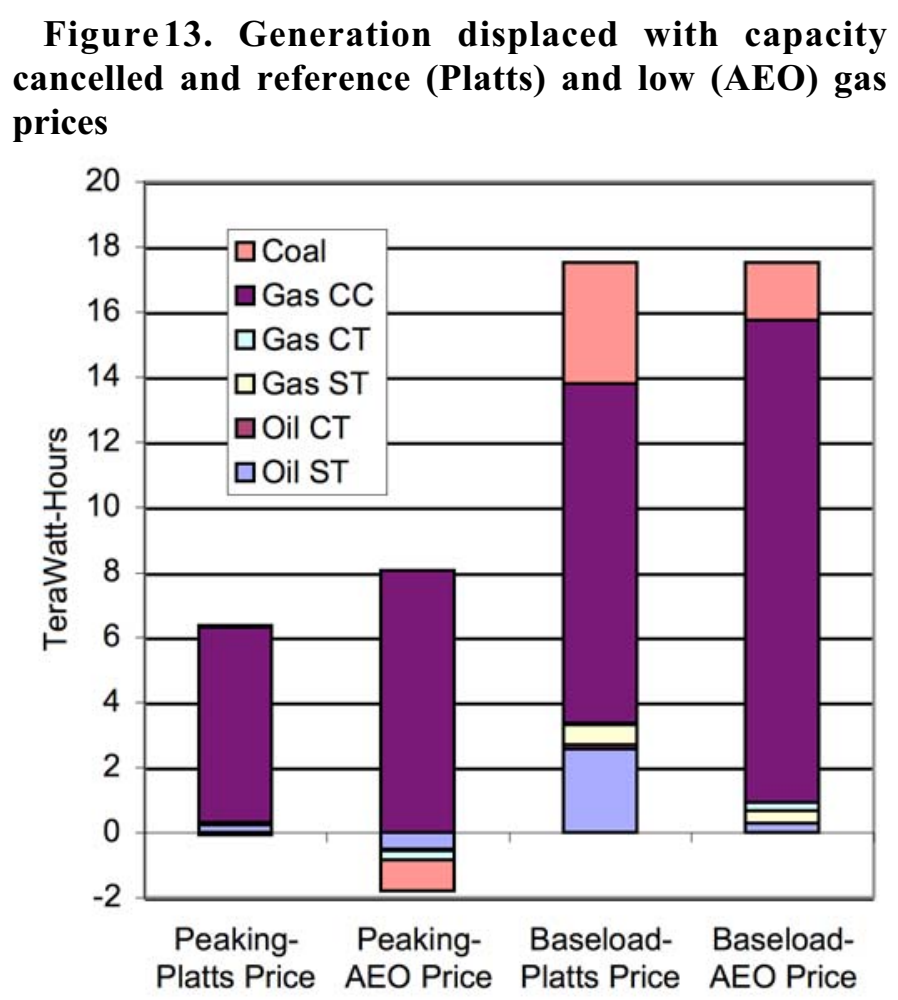

Table 14. Generation displaced with capacity cancelled and low gas prices (GWh)

\begin{tabular}{|l|rr|rr|}
\hline Plant Type & \multicolumn{2}{c}{ Peaking } & \multicolumn{2}{c|}{ Baseload } \\
\hline Coal & -954 & $-15 \%$ & 1761 & $10 \%$ \\
Gas CC & 8052 & $129 \%$ & 14828 & $85 \%$ \\
Gas CT & -277 & $-4 \%$ & 278 & $2 \%$ \\
Gas ST & 3 & $0 \%$ & 362 & $2 \%$ \\
Oil CT & -33 & $-1 \%$ & 15 & $0 \%$ \\
Oil ST & -527 & $-8 \%$ & 277 & $2 \%$ \\
\hline Total & 6264 & $100 \%$ & 17520 & $100 \%$ \\
\hline
\end{tabular}

Table 15. Energy and emissions parameters of displaced generation

\begin{tabular}{|lrr|}
\hline & Peaking & Baseload \\
\hline \hline Avg Displaced & $58 \%$ & $45 \%$ \\
Efficiency & 491 & 995 \\
$\mathrm{CO}_{2}, \mathrm{lb} / \mathrm{MWh}$ & -0.83 & 0.76 \\
$\mathrm{NO}_{x}, \mathrm{lb} / \mathrm{MWh}$ & -4.21 & 2.33 \\
$\mathrm{SO}_{2}, \mathrm{lb} / \mathrm{MWh}$ & \\
\hline
\end{tabular}

The energy and emissions parameters also showed the impact of the cancellations and change in operations (Table 15). While central electricity production decreased by the amount of the DER, 6264 GWh or 21.4 TBtu in the Peaking scenario, efficient gas CC decreased more and inefficient CT and ST production increased. This caused the primary energy use to decline by only 37 TBtu (Table 16), resulting in a quasi-efficiency of $21.4 / 37$ or $58 \%$. Even if CHP was used, the total energy savings was only 8 TBtu. Another crucial factor is that with the increase in coal use to make up for the loss of $\mathrm{CC}$, total $\mathrm{SO}_{2}$ emissions for the Peaking scenario increased as well. However, in both scenarios the $\mathrm{NO}_{\mathrm{X}}$ emissions were reduced, largely due to savings from CHP. 
Table 16. Primary energy use, $\mathrm{CO}_{2}, \mathrm{NO}_{\mathrm{x}}$, and $\mathrm{SO}_{2}$ emissions from $2000 \mathrm{MW}$ of CT-6B with and without CHP if $2000 \mathrm{MW}$ of new $\mathrm{CC}$ capacity is cancelled and gas prices are lower

\begin{tabular}{|l|l|rrrrr|}
\hline \multicolumn{2}{|c|}{} & Dist. Gen. & $\begin{array}{c}\text { Electric } \\
\text { System }\end{array}$ & $\begin{array}{c}\text { Net w/o } \\
\text { CHP }\end{array}$ & $\begin{array}{r}\text { Thermal } \\
\text { System }\end{array}$ & Net w/ CHP \\
\hline \hline Primary Energy, & Peaking DER & 74 & -37 & 38 & -46 & -8 \\
TBtu & Baseload DER & 208 & -134 & 75 & -128 & -53 \\
\hline CO $_{2}$, Mtons & Peaking DER & 4.4 & -1.5 & 2.8 & -2.7 & 0.1 \\
& Baseload DER & 20.8 & -13.4 & 7.5 & -12.8 & -5.3 \\
\hline NO $_{\mathbf{x}}, \mathbf{k T o n s}$ & Peaking DER & 0.8 & 2.6 & 3.4 & -10.5 & -7.1 \\
& Baseload DER & 2.3 & -6.6 & -4.3 & -29.4 & -33.7 \\
\hline SO $_{2}$, kTons & Peaking DER & 0.0 & 13.2 & 13.2 & 0.0 & 13.2 \\
& Baseload DER & 0.0 & -20.4 & -20.4 & 0.0 & -20.4 \\
\hline
\end{tabular}

Since the Peaking DER scenario only lowered the peak demand by 511 MW rather than the full 2000 $\mathrm{MW}$, and the new capacity was operated more as baseload, it becomes more likely that only a fraction of the new CC capacity might be cancelled. To explore the changing displacement, we ran the Peaking scenario with only 1000, MW, $511 \mathrm{MW}$, and $0 \mathrm{MW}$ of CC cancelled. The results are shown in Figure 14. As the amount of cancelled CC capacity was reduced, the amount of CC generation displaced dropped as well. Then several other technologies were also reduced; $\mathrm{CC}$ generation represented $129 \%, 87 \%, 69 \%$, and $50 \%$ of the total generation reduction as cancelled capacity dropped from 2000 to $0 \mathrm{MW}$.

Figure 14. Displaced generation with 2000 MW of Peaking DER, low gas prices, and varying amounts of CC capacity cancelled

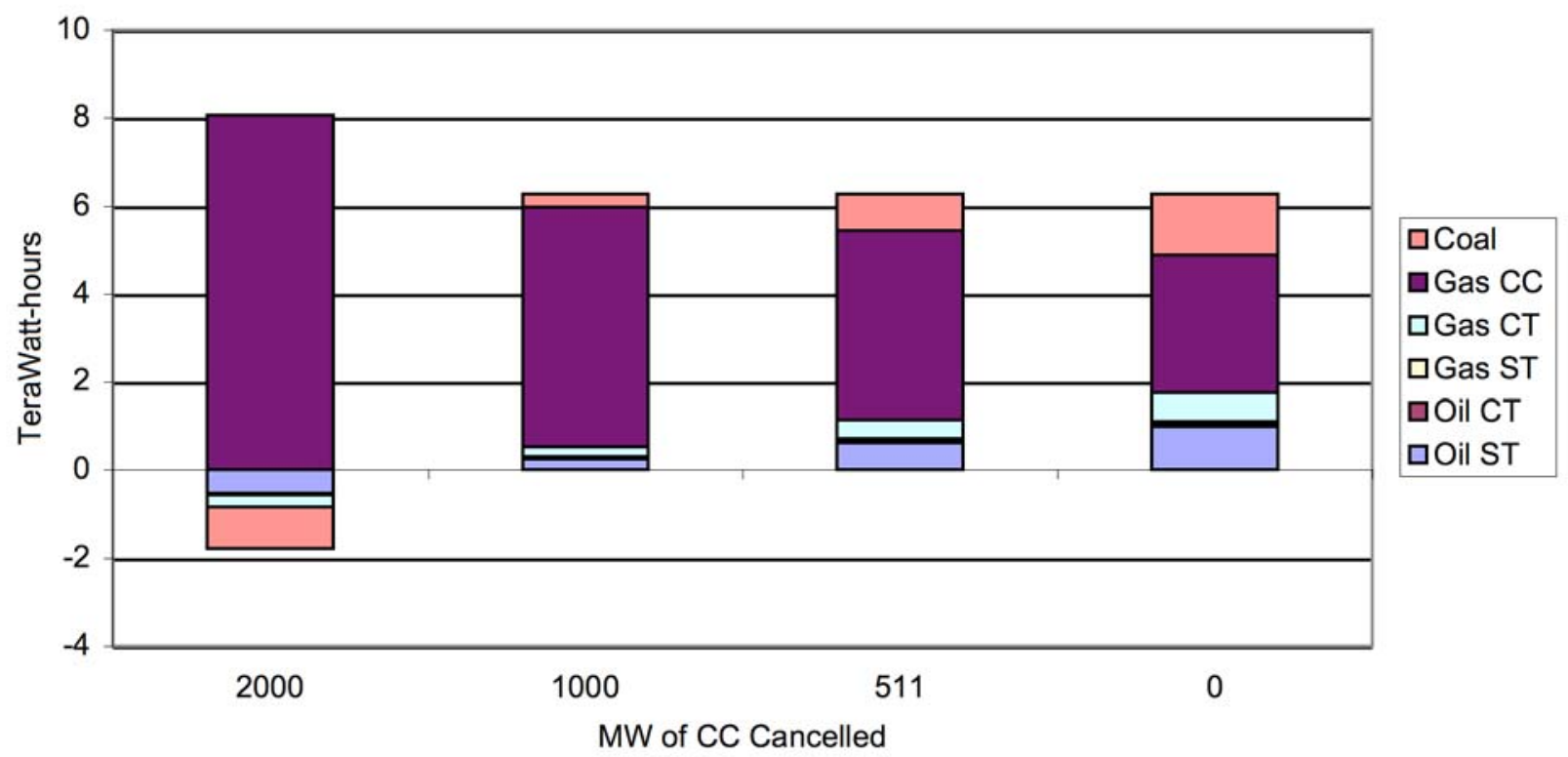

\subsubsection{Capacity Reserve Margin}

In our reference scenarios we increased customer demands by $10 \%$ above the amount predicted for the MAAC region to represent sales from the region and to more fully utilize the plants being built in the region. However, it may occur that the plants are built but sales do not increase, leaving the region with an even larger amount of surplus capacity than in the reference scenarios. We removed the $10 \%$ increase and reran the scenario with no DER and with 2000 MW of DER causing the cancellation of new CC plants. While the reference scenario had a reserve margin of $18 \%$, the new set of cases had a reserve margin of $30 \%$. Figure 15 shows the change in central generation for both the reference demand scenarios 
and with $10 \%$ lower demands. Table 17 shows the actual amounts of reduction for the various technologies under reduced demands.

Figure 15. Generation displaced with new CC Table 17. Generation displaced with capacity cancelled and reference and low customer capacity cancelled and low customer demands

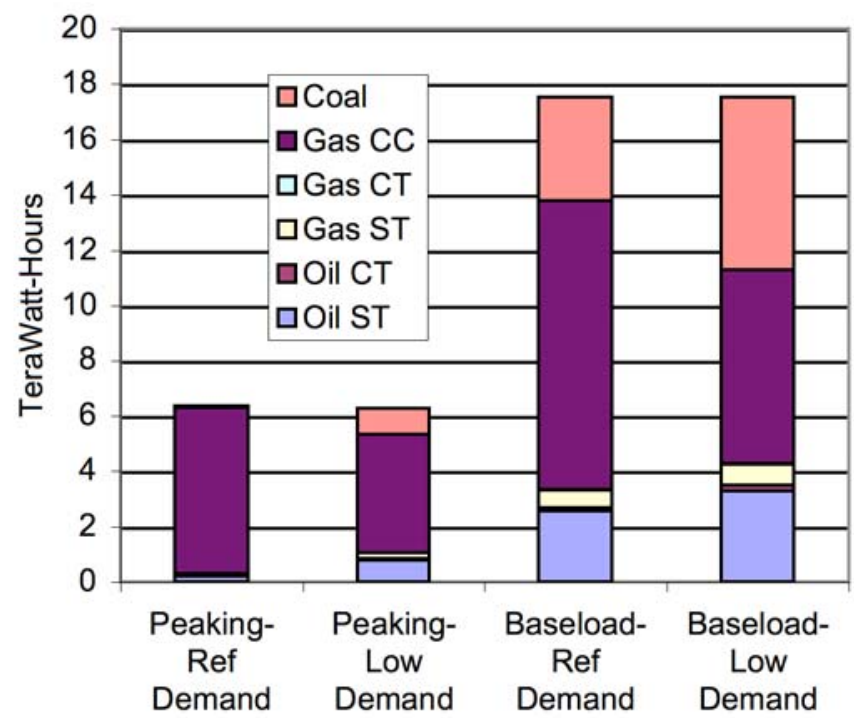
demands (GWh)

\begin{tabular}{|l|rr|rr|}
\hline Plant Type & \multicolumn{2}{c}{ Peak } & \multicolumn{2}{c|}{ Baseload } \\
\hline Coal & 938 & $15 \%$ & 6237 & $36 \%$ \\
Gas CC & 4277 & $68 \%$ & 7015 & $40 \%$ \\
Gas CT & -10 & $0 \%$ & 6 & $0 \%$ \\
Gas ST & 229 & $4 \%$ & 764 & $4 \%$ \\
Oil CT & 57 & $1 \%$ & 203 & $1 \%$ \\
Oil ST & 773 & $12 \%$ & 3295 & $19 \%$ \\
\hline Total & 6264 & & 17520 & \\
\hline
\end{tabular}

With lower customer demands and higher reserve margins, some of the lower cost coal and oil plants were on the margin more often so were reduced when the DER further reduced demand. New CC capacity had a lower capacity factor than in the reference scenarios, $15 \%$ instead of $27 \%$, so the displaced power came from other, higher emitting technologies besides CC. Consequently, emissions reductions were better when DER was used with the lower customer demands than with the reference demands (Table 18 versus Table 9).

Table 18. Primary energy use, $\mathrm{CO}_{2}, \mathrm{NO}_{\mathrm{x}}$, and $\mathrm{SO}_{2}$ emissions from $2000 \mathrm{MW}$ of CT-6B with and without CHP if $2000 \mathrm{MW}$ of new $\mathrm{CC}$ capacity is cancelled and customer demands are lower

\begin{tabular}{|l|l|rrrrr|}
\hline \multicolumn{2}{|c|}{} & Dist. Gen. & $\begin{array}{c}\text { Electric } \\
\text { System }\end{array}$ & $\begin{array}{c}\text { Net w/o } \\
\text { CHP }\end{array}$ & $\begin{array}{c}\text { Thermal } \\
\text { System }\end{array}$ & Net w/ CHP \\
\hline \hline Primary Energy, & Peaking DER & 74 & -53 & 22 & -46 & -24 \\
TBtu & Baseload DER & 208 & -163 & 46 & -128 & -82 \\
\hline $\mathbf{C O}_{2}$, Mtons & Peaking DER & 4.4 & -3.8 & 0.6 & -2.7 & -2.1 \\
& Baseload DER & 20.8 & -16.3 & 4.6 & -12.8 & -8.2 \\
\hline NO $_{\mathbf{x}}, \mathbf{k T o n s}$ & Peaking DER & 0.8 & -3.8 & -3.0 & -10.5 & -13.5 \\
& Baseload DER & 2.3 & -20.8 & -18.5 & -29.4 & -47.9 \\
\hline $\mathbf{S O}_{2}, \mathbf{k T o n s}$ & Peaking DER & 0.0 & -13.8 & -13.8 & 0.0 & -13.8 \\
& Baseload DER & 0.0 & -84.1 & -84.1 & 0.0 & -84.1 \\
\hline
\end{tabular}




\section{Results \& Conclusions}

This analysis shows that in most cases the introduction of DER does not lead to the displacement solely of new gas $\mathrm{CC}$ generation, even if gas CC capacity is cancelled as a result of the DER. And even if the DER does displace $\mathrm{CC}$ generation, the net impact is lower $\mathrm{NO}_{\mathrm{X}}, \mathrm{SO}_{2}$, and $\mathrm{CO}_{2}$ emissions, especially when including the CHP potential benefits of DER.

Two main DER scenarios were evaluated: DER operating all the time (Baseload) and DER operating only during weekdays (Peaking). In response to the DER, three possible reactions by the central grid were evaluated: no reduction in central generation capacity, cancellation of an equivalent amount of new capacity, and retirement of an equivalent amount of old capacity. Sensitivities to fuel prices, amount of cancellation, and base level of demand were evaluated.

With Baseload DER, all types of central generation were displaced to some extent, regardless of whether new plants were cancelled, old plants retired, gas prices set high or low, or customer demands lowered (Figure 16). Cancellation of new $\mathrm{CC}$ had a small impact on the relative amount of displaced generation as did low gas prices, but the largest impact was if there was both cancellation and low gas prices. If prices for gas remain high relative to fuel oil and coal, then DER will succeed in displacing these other, dirtier technologies instead of just new gas-fired production.

Figure 16. Central generation displaced by DER operating year-round in different scenarios

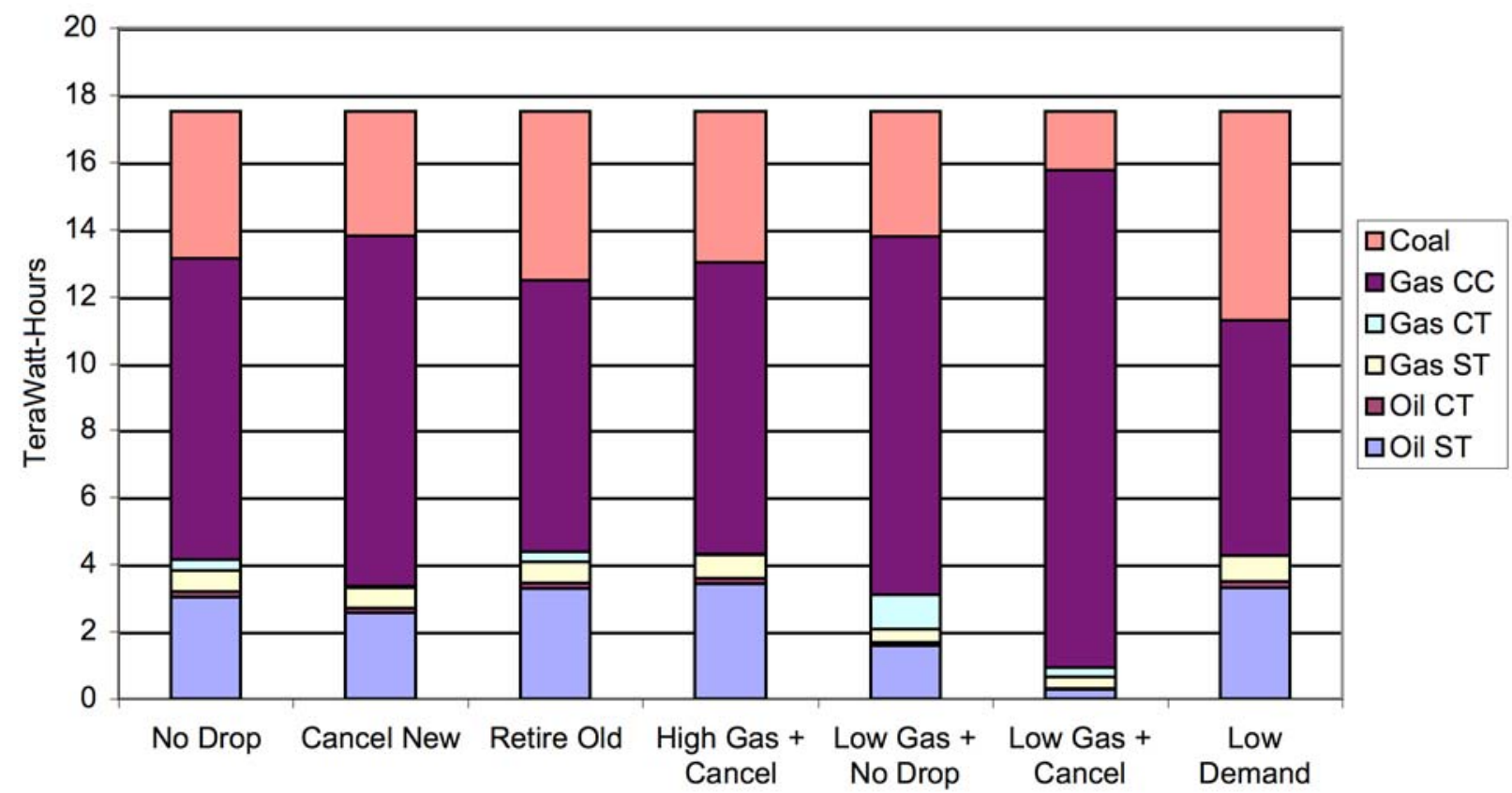

Because other technologies were displaced besides new, clean gas-fired $\mathrm{CC}$, primary energy use went down and emissions of critical pollutants $\left(\mathrm{SO}_{2}, \mathrm{NO}_{\mathrm{X}}\right.$, and $\left.\mathrm{CO}_{2}\right)$ decreased as well. A key advantage of DER is the capability to use the exhaust heat of the electric generation for other thermal uses at the site. If this displaces gas-fired combustion as in typical boilers then energy and emission savings are even more pronounced. Figure 17 shows the net emissions for the Baseload DER under each of the scenarios analyzed. Both the DER emissions and the Thermal System savings were the same in each case because the equal amount of production. In all cases, the emissions from the electric system went down as well, as the DER displaced other generation. The scenario with the smallest net impact was the one with low gas 
prices and cancellation of new gas-fired CC capacity. Since this capacity was even cleaner than the DER then there were only small emissions reductions from that capacity, but the displacement of other technologies besides CC (i.e., coal, oil, and other gas technologies, see Figure 16) contributed as well. Reductions in primary energy and other emissions show similar patterns to the $\mathrm{NO}_{\mathrm{X}}$ emission results.

Figure 17. Net $\mathrm{NO}_{\mathrm{x}}$ emissions from Baseload DER under varying scenarios

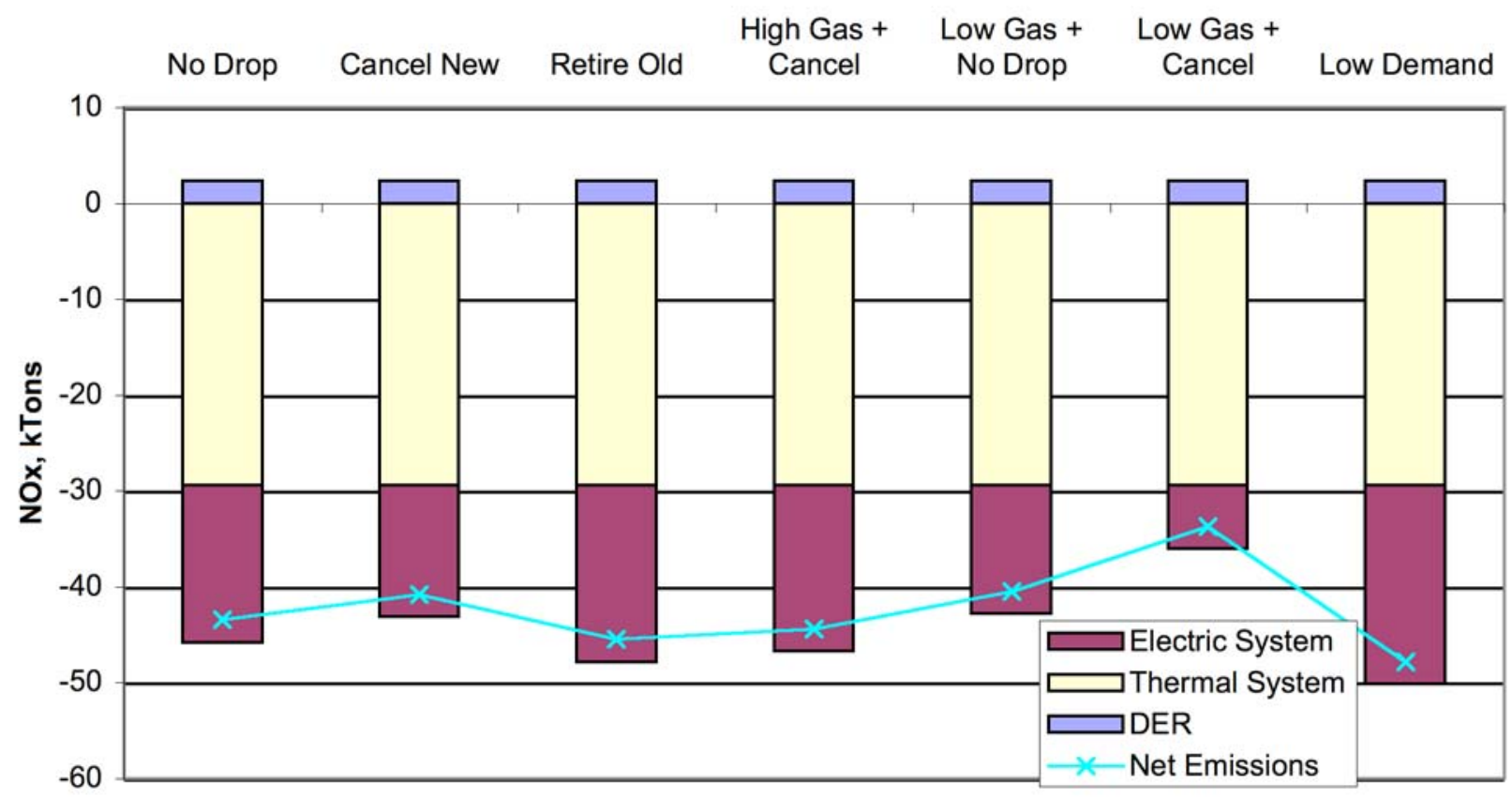

With DER operating only during weekdays, the situation was more complex (Figure 18). Cancellation of $2000 \mathrm{MW}$ of new capacity under the reference power prices resulted in roughly equivalent displacement by DER. Retirements or simply increased reserves resulted in other technologies besides Gas CC being displaced. Although $2000 \mathrm{MW}$ of DER were deployed, peak demands only dropped $511 \mathrm{MW}$. (Weekday hours are only $36 \%$ of the year.) If cancelled capacity would have operated for a larger percent of that time if it had not been cancelled (such as in the scenario with low gas prices) then its cancellation caused other technologies to increase their production. However, even at low prices, if cancellations were closer to the reduction in the peak demand, then all technologies had some displacement from the DER.

The Peaking DER sets of scenarios show a similar pattern emissions reductions to the Baseload scenarios, but because DER displaced a higher proportion of new CC when the CC was cancelled, and because the Peaking DER generated less power and thermal energy, the net emissions savings were less (Figure 19). Most unusual was the scenario with low gas prices and canceling $2000 \mathrm{MW}$ of new CC. Because this scenario resulted in increased generation from coal and other central plants, the emissions from the electric system increased rather than decreased. However, the savings from the modeled thermal system more than made up for the additional emissions and the net emissions were negative. 
Figure 18. Central generation displaced by DER operating weekdays only in different scenarios

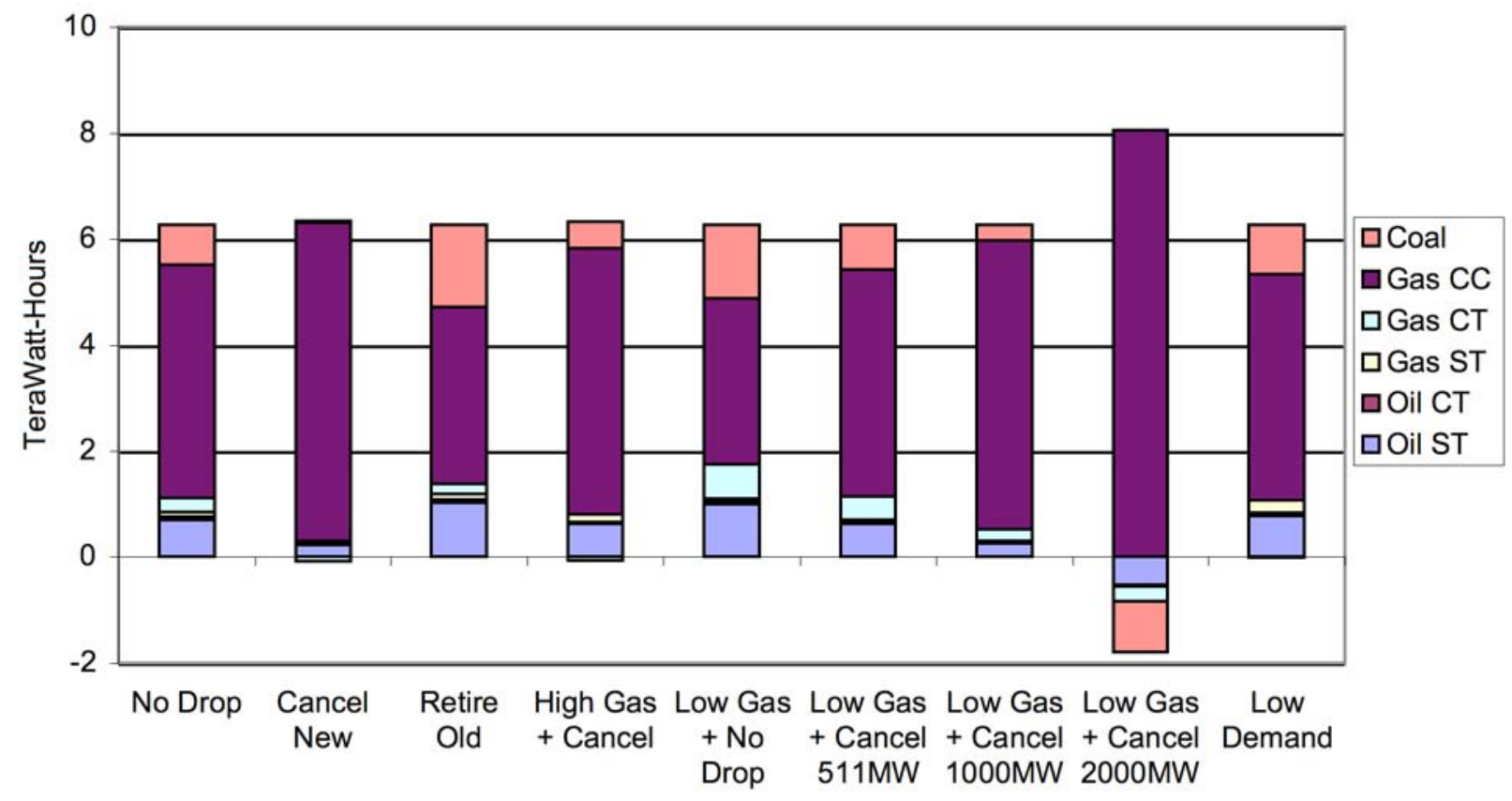

Figure 19. Net $\mathrm{NO}_{\mathrm{x}}$ emissions from Peaking DER under varying scenarios

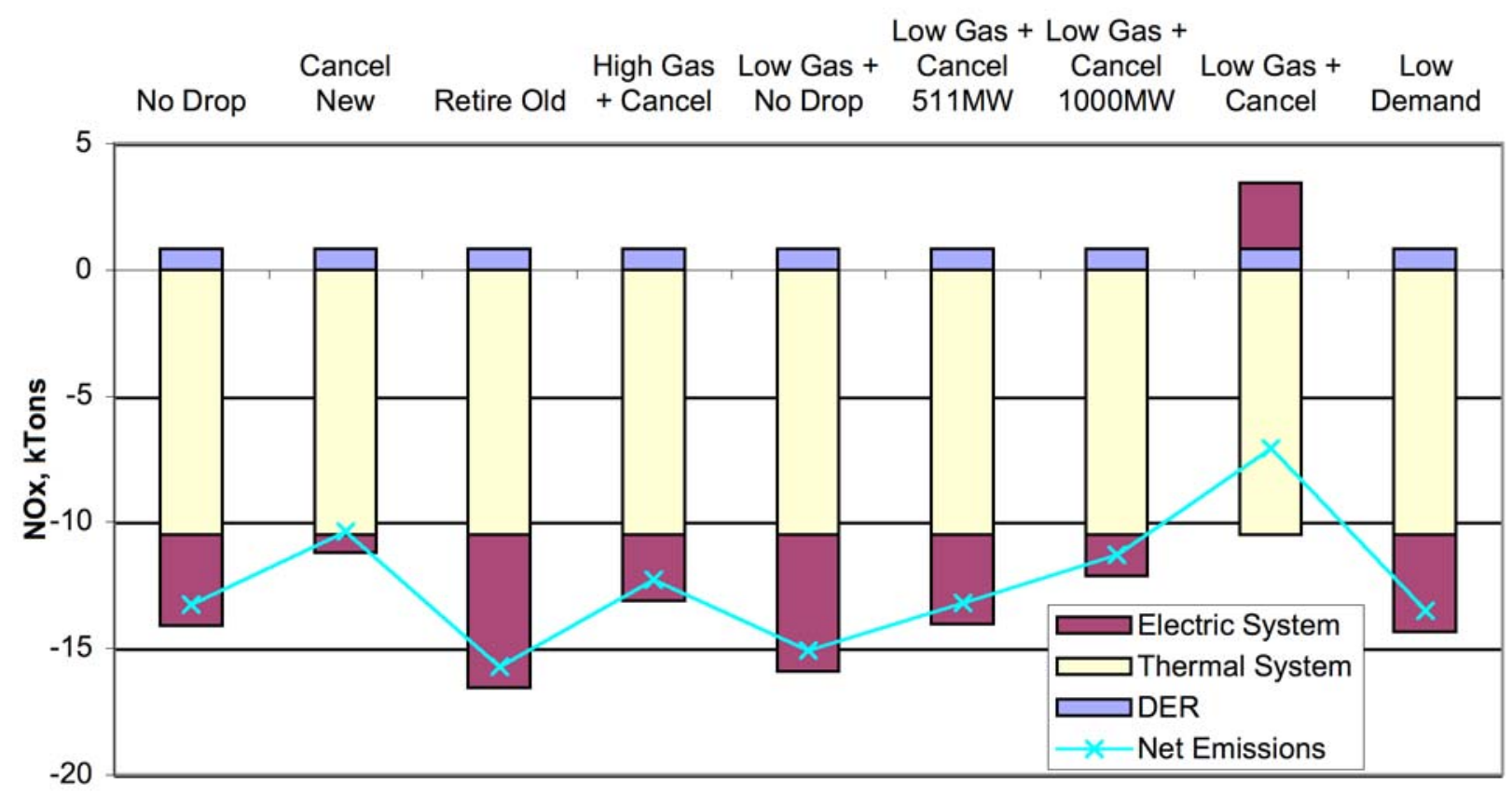

Another way to view the results of all the scenarios is the net change in energy or emissions as a fraction of the gross energy use or emissions of the DER (Table 19). With no CHP, net energy use and $\mathrm{CO}_{2}$ emissions were generally positive but were negative when thermal energy from DER was used in CHP. $\mathrm{NO}_{\mathrm{X}}$ emissions from DER were very low so that net emissions were negative even with just electricity generation. 
Table 19. Net changes in energy and emissions as a fraction of the DER's amounts for all scenarios studied. Positive means a net increase and negative means a net savings. $\mathrm{NO}_{\mathrm{x}}$ changes are shown as a ratio to the DER emissions. $\mathrm{SO}_{2}$ changes are "+" or "_" since DER emits no $\mathrm{SO}_{2}$.

\begin{tabular}{|c|c|c|c|c|c|c|c|c|c|c|c|}
\hline \multirow{2}{*}{$\begin{array}{l}\text { System } \\
\text { change }\end{array}$} & \multirow{2}{*}{\begin{tabular}{|c|} 
Fuel \\
prices
\end{tabular}} & \multirow[t]{2}{*}{ Demand } & \multirow{2}{*}{$\begin{array}{l}\text { DER } \\
\text { mode }\end{array}$} & \multicolumn{2}{|c|}{ Primary Energy } & \multicolumn{2}{|c|}{$\mathrm{CO}_{2}$} & \multicolumn{2}{|c|}{$\mathrm{NO}_{\mathrm{x}}$} & \multicolumn{2}{|c|}{$\mathrm{SO}_{2}$} \\
\hline & & & & $\begin{array}{l}\mathrm{No} \\
\mathrm{CHP}\end{array}$ & $\begin{array}{l}\text { With } \\
\mathrm{CHP} \\
\end{array}$ & $\begin{array}{c}\mathrm{No} \\
\mathrm{CHP} \\
\end{array}$ & $\begin{array}{l}\text { With } \\
\mathrm{CHP} \\
\end{array}$ & $\begin{array}{c}\mathrm{No} \\
\mathrm{CHP} \\
\end{array}$ & $\begin{array}{l}\text { With } \\
\text { CHP }\end{array}$ & $\begin{array}{c}\mathrm{No} \\
\mathrm{CHP}\end{array}$ & $\begin{array}{l}\text { With } \\
\mathrm{CHP} \\
\end{array}$ \\
\hline \multirow{2}{*}{ No cancel } & \multirow{2}{*}{$\begin{array}{l}\text { Platts } \\
\text { (Ref) }\end{array}$} & \multirow{2}{*}{$\begin{array}{r}2006 \\
+10 \%\end{array}$} & Peak & $28 \%$ & $-32 \%$ & $14 \%$ & $-48 \%$ & $-4 x$ & $-17 x$ & - & - \\
\hline & & & Base & $24 \%$ & $-38 \%$ & $24 \%$ & $-38 \%$ & $-6 x$ & $-19 x$ & - & - \\
\hline \multirow{2}{*}{$\begin{array}{c}\text { Cancel } \\
2000 \text { new }\end{array}$} & \multirow{2}{*}{$\begin{array}{l}\text { Platts } \\
\text { (Ref) }\end{array}$} & \multirow{2}{*}{$\begin{array}{r}2006 \\
+10 \%\end{array}$} & Peak & $41 \%$ & $-22 \%$ & $36 \%$ & $-23 \%$ & $+.1 x$ & $-13 x$ & - & - \\
\hline & & & Base & $27 \%$ & $-34 \%$ & $27 \%$ & $-34 \%$ & $-5 x$ & $-18 x$ & - & - \\
\hline \multirow{2}{*}{$\begin{array}{c}\text { Retire } \\
2000 \text { old }\end{array}$} & \multirow{2}{*}{$\begin{array}{l}\text { Platts } \\
\text { (Ref) }\end{array}$} & \multirow{2}{*}{$\begin{array}{r}2006 \\
+10 \%\end{array}$} & Peak & $24 \%$ & $-38 \%$ & $-2 \%$ & $-61 \%$ & $-6 x$ & $-20 x$ & - & - \\
\hline & & & Base & $22 \%$ & $-39 \%$ & $22 \%$ & $-39 \%$ & $-7 x$ & $-20 x$ & - & - \\
\hline \multirow{2}{*}{$\begin{array}{c}\text { Cancel } \\
2000 \text { new }\end{array}$} & \multirow{2}{*}{$\begin{array}{l}\text { STEO } \\
\text { (High) }\end{array}$} & \multirow{2}{*}{$\begin{array}{r}2006 \\
+10 \%\end{array}$} & Peak & $35 \%$ & $-27 \%$ & $23 \%$ & $-36 \%$ & $-2 x$ & $-15 x$ & - & - \\
\hline & & & Base & $24 \%$ & $-38 \%$ & $24 \%$ & $-38 \%$ & $-7 x$ & $-19 x$ & - & - \\
\hline \multirow{2}{*}{$\begin{array}{c}\text { Cancel } \\
2000 \text { new }\end{array}$} & \multirow{2}{*}{$\begin{array}{l}\text { AEO } \\
\text { (Low) }\end{array}$} & \multirow{2}{*}{$\begin{array}{l}2006 \\
+10 \%\end{array}$} & Peak & $51 \%$ & $-11 \%$ & $64 \%$ & $2 \%$ & $+4 x$ & $-9 x$ & + & + \\
\hline & & & Base & $36 \%$ & $-25 \%$ & $36 \%$ & $-25 \%$ & $-2 x$ & $-15 x$ & - & - \\
\hline $\begin{array}{c}\text { Cancel } \\
1000 \text { new }\end{array}$ & $\begin{array}{l}\text { AEO } \\
\text { (Low) }\end{array}$ & $\begin{array}{l}2006 \\
+10 \%\end{array}$ & Peak & $36 \%$ & $-26 \%$ & $31 \%$ & $-31 \%$ & $-1 x$ & $-14 x$ & - & - \\
\hline $\begin{array}{c}\text { Cancel } \\
511 \text { new }\end{array}$ & $\begin{array}{l}\begin{array}{l}\text { AEO } \\
\text { (Low) }\end{array} \\
\end{array}$ & $\begin{array}{r}2006 \\
+10 \% \\
\end{array}$ & Peak & $29 \%$ & $-32 \%$ & $15 \%$ & $-46 \%$ & $-3 x$ & $-16 x$ & - & - \\
\hline \multirow{2}{*}{ No cancel } & \multirow{2}{*}{$\begin{array}{l}\text { AEO } \\
\text { (Low) }\end{array}$} & \multirow{2}{*}{$\begin{array}{r}2006 \\
+10 \%\end{array}$} & Peak & $23 \%$ & $-39 \%$ & $1 \%$ & $-61 \%$ & $-6 x$ & $-18 x$ & - & - \\
\hline & & & Base & $28 \%$ & $-34 \%$ & $28 \%$ & $-34 \%$ & $-5 x$ & $-18 x$ & - & - \\
\hline \multirow{2}{*}{$\begin{array}{c}\text { Cancel } \\
2000 \text { new }\end{array}$} & \multirow{2}{*}{$\begin{array}{l}\text { Platts } \\
\text { (Ref) }\end{array}$} & \multirow{2}{*}{2006} & Peak & $30 \%$ & $-32 \%$ & $14 \%$ & $-48 \%$ & $-4 x$ & $-17 x$ & - & - \\
\hline & & & Base & $22 \%$ & $-39 \%$ & $22 \%$ & $-39 \%$ & $-8 x$ & $-21 x$ & - & - \\
\hline \multicolumn{4}{|c|}{ Average of all Scenarios } & $30 \%$ & $-32 \%$ & $24 \%$ & $-37 \%$ & $-4 x$ & $-17 x$ & & \\
\hline
\end{tabular}

Four scenario results are highlighted. Of the reference cases, the case with peaking DER and cancellation of new CC capacity had the least savings. Without $\mathrm{CHP}$, even $\mathrm{NO}_{\mathrm{X}}$ emissions were higher with DER, but with CHP savings were shown in all categories. On the other hand, if old plants were retired, then net savings were high. The most damaging scenario to DER was with the peaking scenario, low gas prices, and cancellation of $2000 \mathrm{MW}$ of new CC. The results show a net increase in all categories without CHP and an increase in $\mathrm{CO}_{2}$ and $\mathrm{SO}_{2}$ emissions even with $\mathrm{CHP}$. This was likely the scenario that many have assumed when considering the benefits of DER, but only appeared with outdated assumptions on gas prices. 
A key concern with DER is that while net emissions decline, emissions at the particular site may increase. In our analysis, this would only occur if the DER did not displace any thermal system production through CHP or if the displaced thermal process was lower emitting than the DER. In these situations it would be useful for regulations to recognize the overall reduction, perhaps by giving some type of credit for the central electric system emission reductions.

In conclusion, our analysis shows that even if new, gas-fired CC capacity is cancelled in proportion to the impact of DER on system loads, energy is saved and net emissions are reduced. Utilizing the exhaust heat from the DER compounds the savings and makes DER a valuable component of the country's energy portfolio. 


\section{References}

EIA (Energy Information Administration) 2002, Annual Energy Outlook 2003 with Projections to 2025, DOE/EIA-0383(2003), U.S. Department of Energy, Washington, D.C. December.

$<$ http://www.eia.doe.gov/oiaf/aeo/index.html>

$<$ ftp://eia.doe.gov/oiaf/aeo/aeo2003.exe>

EIA 2003a The Assumptions to the Annual Energy Outlook 2003, DOE/EIA-0554(2003), U.S.

Department of Energy, Washington, D.C., January.

$<$ http://www.eia.doe.gov/oiaf/aeo/assumption/index.html>

EIA 2003b, National Energy Modeling System: An Overview 2003, DOE/EIA-0581 (2003), U.S. Department of Energy, Washington, DC, March.

http://www.eia.doe.gov/oiaf/aeo/overview/introduction.html

EIA2003c, Short-Term Energy Outlook, U.S. Department of Energy, Washington, DC, June.

$<$ http://www.eia.doe.gov/pub/forecasting/steo/oldsteos/jun03.pdf $>$

EPA (Environmental Protection Agency) 2001, E-GRID 2000PC, Version 2.0, Office of Atmospheric Programs, September. $<\underline{\text { http://www.epa.gov/airmarkets/egrid/> }}$

EPA 2002, Documentation of EPA Modeling Applications (V.2.1) Using the Integrated Planning Model, EPA 430/R-02-004, Environmental Protection Agency, March

$<$ http://www.epa.gov/airmarkets/epa-ipm/>

Hadley, S. and E. Hirst 1998, ORCED: A Model to Simulate the Operations and Costs of Bulk-Power Markets, ORNL/CON-464, Oak Ridge National Laboratory, Oak Ridge, TN, June.

$<$ http://www.ornl.gov/orced/index.html>

Hadley, S.W.,J.W. Van Dyke, W.P. Poore, and T. K. Stovall, 2003, Quantitative Assessment of Distributed Energy Resource Benefits, ORNL/TM-2003/20, Oak Ridge National Laboratory, Oak Ridge, TN, May.

PJM 2002 PJM - Hourly Load Data, Pennsylvania, New Jersey, Maryland Interconnection LLC, $<$ http://www.pjm.com/markets/jsp/loadhryr.jsp $>$

Platts 2003, Powerdat Database, Platts, Inc., Boulder, Colo.

Reuters 2003, "Reliant mulls mothballing some U.S. power plants", August 12.

$<$ http://reuters.com/financeQuoteCompanyNewsArticle.jhtml? storyID=3266995\&ric=RRI.N\&infotype $=n$ ews\&compname $=$ RELIANT + RSCS $>$ 